\title{
Análisis de la problemática de los adolescentes desde la educación y la salud pública, del partido de Malvinas argentinas - Año 2018
}

Analysis of the educational and public health problems faced by adolescents from the district of Malvinas Argentinas - 2018

\section{ISSN 2071-8748 \\ E-ISSN 2218-3345 \\ (c) (9) (2) \\ BY NC SA}

URI: http://hdl.handle.net/11298/980

DOI: https://doi.org/10.5377/entorno.v0i67.7492
Mg. Dardo Ernesto Ledesma Director del Centro de Estudios en Administración de la Salud Universidad CAECE

ORCID:0000-0003-2685-7363

Dra. Marcela Victoria Tapiola ${ }^{2}$ Jefa del Servicio de Consultorios Externos

Hospital de Pediatría Dr. Claudio Zin Partido de Malvinas Argentinas Provincia de Buenos Aires ORCID: 0000-0002-7005-953X

Colaboradores:

Dra. Silvia Daveggio Directora del Hospital de Pediatría Dr. Claudio Zin

Partido de Malvinas Argentinas Dra. Selva Alejandra Pratto Directora de Primer Nivel de Atención

Partido de Malvinas Argentinas Lic. Marcela Liever,

Especializada en Estadística Aplicada

Recibido: 12 de agosto 2018 Aprobado: 18 de mayo 2019

1 Licenciado en Gestión Educativa. Máster en Dirección de Empresas. IAE. Especializado y Magister en Metodología de Investigación Científica. Universidad Nacional de Lanús. Director y docente de postgrados de Administración Hospitalaria y Sistemas de Salud. Universidad CAECE. eledesma@caece.edu.ar Argentina.

2 Dra. Marcela Victoria Tapiola. Especialista en Pediatría y Hebitaría de la Universidad de Buenos Aires. Jefe del Servicio de Consultorios Externos. Hospital de Pediatría Dr. Claudio Zin. Partido de Malvinas Argentinas, Prov. de Buenos Aires. mtapiolacarmona@gmail.com Argentina. 


\begin{abstract}
Resumen
El propósito de esta investigación es conocer las expectativas y necesidades habituales de los estudiantes y pacientes adolescentes del área centro del partido de Malvinas Argentinas, primer cordón del conurbano bonaerense, y cómo se los atiende. Se estudiarán los registros y las actividades que se realizan para mejorar la asistencia educativa y sanitaria. La metodología de investigación será exploratoria, se empleará un diseño mixto y se utilizarán entrevistas, encuestas y cuestionarios, con instrumentos ya validados mediante el análisis estadístico Alfa de Cronbach, utilizando el software SPSS 15.0 y ATLAS.ti. 8. Se espera alcanzar evidencias relevantes y replicables que posibiliten mejoras sustanciales en el sistema educativo y de la salud pública en el desarrollo futuro de programas dirigidos hacia la prevención y educación de los adolescentes y la comunidad.
\end{abstract}

\section{Palabras clave}

Escuelas de salud pública, Sociología de la educación, problemas sociales, violencia en la educación.

\section{Base teórica}

La problemática de los adolescentes en Argentina es importante, y en ciertos casos grave, ya que lo profundizan los aspectos económicos, sociales, educativos y el estar sujetos a los medios de comunicación y las nuevas tecnologías. El paso de la niñez a la adultez, significa superar los criterios de formación dirigidas por sus progenitores, por una conducta que él mismo quiere determinar. Así, es común que se los señale rebeldes, inseguros, insolentes o independientes, y, por otro lado, se les reconozcan su inclinación a colaborar, a ser altruistas y voluntarios para ayudar al compañero o al que necesita.

El presente trabajo de investigación, desarrollado en un sector carenciado de la provincia de Buenos Aires, y con notables similitudes a una extensa población del conurbano bonaerense donde residen millones de niños y adolescentes, tiene por objetivos los siguientes:

\section{Abstract}

The purpose of this research is to know the expectations and usual needs of students and adolescent patients in the downtown area of the district of Malvinas Argentinas, the first division of the metropolitan area of Buenos Aires, and how they are served. The records and activities undertaken to improve education and health care will be studied. The research methodology is exploratory; a mixed design will be used and interviews, surveys and questionnaires, with already validated instruments through the Cronbach's Alpha will be used, using SPSS 15.0 and ATLAS.ti. 8. It is expected to reach relevant and replicable evidence that may foster substantial improvement in the educational system and the public health in the future development of programs aimed at the prevention and education of adolescents in the community.

\section{Keywords}

Schools of public health, sociology of education, social problems, violence in education.

a. Describir el contexto general en que viven y se desarrollan los adolescentes de un sector carenciado del partido de Malvinas Argentinas.

b. Analizar las principales realidades que experimentan los adolescentes y que se manifiestan en el ámbito educativo.

c. Explorar la atención que reciben desde la salud pública en las unidades funcionales del partido de Malvinas Argentinas.

Para alcanzar los citados objetivos y comenzar a conocer el marco teórico y las diferentes vivencias que experimentan a diario los adolescentes, se analizarán aquellos aspectos considerados relevantes, entre ellos los siguientes:

\section{La familia y la escuela}

En la actualidad, ciertos pensadores sugieren que tanto la familia como la escuela en Argentina están en crisis y que 
deben cambiarse las miradas y creencias que se tienen de ambas instituciones. Esta creencia se fundamenta por los resultados que se conocen en cuanto al rendimiento de los alumnos en la escuela, la que debe transformarse, donde se cuestiona su estructura, la organización y sus formas antiguas de plantear el proceso de enseñanza-aprendizaje, y se sostiene que debe adaptarse a los tiempos que corren y pensar mucho más en el futuro.

En cuanto a la familia, se evidencia la aceptación de sus cambios y se reconocen las circunstancias difíciles por las que atraviesa, donde se observa a mujeres jefas de hogar, familias ensambladas, padres ausentes o desocupados, como también con determinadas enfermedades mentales 0 adicciones.

Ante esta situación en permanente cambio, cabe pensar cómo y con qué actitud habrá que repensar la construcción del futuro para los niños y jóvenes en la actualidad. Sí, resulta imprescindible contar con mejoras sustanciales, en especial en las escuelas, y aceptar y apoyar las realidades familiares que conviven y se desarrollan en las comunidades.

Es necesario volver a considerar los fines de ambas instituciones y profundizar la interacción constructiva para alcanzar cambios efectivos y verdaderos. En cuanto a la familia, se ha sostenido siempre que será el amor el verdadero fundamento sobre el cual se sostendrán sus integrantes, donde los esposos procurarán la subsistencia de la familia, asegurarán el cuidado de sus hijos, sus hábitos saludables, les inculcarán el respeto, la honestidad, solidaridad y la libertad.

Su fin esencial será formar personas íntegras, para que puedan subsistir por sí mismas y lograr diseñar su propio proyecto de vida, construyendo su ámbito saludable y necesario para que le sea posible. No obstante, en la actualidad también puede observarse que la familia puede constituirse en un ámbito de violencia física y psíquica, donde uno o ambos padres pueden abandonar a sus hijos, afectando sustancialmente las necesarias crianzas amorosas, perjudicando desarrollos positivos y dejando librados al azar a sus hijos, a su circunstancias, inmaduros, desequilibrados y completamente dependientes de su entorno, su contexto, muchas veces altamente perjudiciales.

Sus consecuencias serán que los adolescentes puedan concurrir a la escuela con el estigma de su situación familiar y las influencias del contexto en el cual se está desarrollando, su barrio, la esquina en que se reúnen, y que incidirán en expresarse mediante conductas que evidencian la satisfacción o insatisfacción que vive, en la valoración de sí mismo y la consideración a los otros, como también en la actitud ante el estudio, el trabajo y la capacidad para soportar límites y frustraciones.

Es indudable que los hijos de padres separados o ausentes pueden sufrir muchísimo las consecuencias del colapso familiar; las mismas circunstancias la pueden vivir aquellos hijos de padres formalmente unidos en matrimonio, pero que se encuentran sin comunicación afectiva, sin amor, pautas morales y éticas, o en entornos agresivos.

Por su parte la comunidad educativa, la escuela, sus directivos y sus docentes, tienen que lograr transmitir conocimientos para el ahora y el futuro, y apoyar la actividad socializadora que ha debido realizarse en el ámbito de la familia, o bien, reformularla y fortalecerla mediante educación en valores.

No obstante, y reflexionando sobre el contexto general, se sabe que los resultados, en cuanto al rendimiento de la escuela a nivel medio, son deficitarios. Son conocidos los resultados poco tranquilizadores de las evaluaciones, que desde el Ministerio de Educación se efectúan. Todos los medios de comunicación escritos o visuales, en Argentina, informan que solo la mitad de los alumnos de nivel secundario finalizarán y aprobarán sus estudios, siendo menor aún en las provincias y en los sectores más carenciados.

Paralelamente, la prensa señala la pobreza de conocimientos con que los alumnos egresan de la escuela y sus dificultades para obtener trabajo, como también para el ingreso y posterior desempeño en la universidad. No solo faltan conocimientos de Historia, Geografía o Ciencias, sino que tampoco saben redactar ni interpretar lo que leen, ni confeccionar un informe de investigación. Los alumnos no aprenden; la escuela no cumple con su fin básico, que es enseñar.

Entre sus exigencias, la escuela tiene que proponer la enseñanza de las ciencias, las tecnologías y los idiomas, pero en mayor medida aún promover el trabajo en equipo, analizando y logrando conclusiones realistas sobre cómo solucionar problemas, la toma de decisiones, cómo sobreponerse a las situaciones de violencia, evitar y superar las adicciones, y cómo conocer con adecuada claridad 
la educación sexual y reproductiva, los hábitos de vida saludables y asumir sus responsabilidades para el cuidado de la salud.

Hoy, más que nunca, las exigencias a la escuela también incluyen promover y crear la disciplina del esfuerzo, formarse continuamente para el cambiante mundo del trabajo y poseer una actitud ética para saber valorar, evaluar y decidir con fundamentos realistas. Otros aspectos significativos serán crear conciencia en el valor que tiene tanto su vida personal, artística y expresiva, social, profesional y laboral como también el vivir en libertad y en un sistema democrático estable y continuado en el tiempo.

Es evidente que, en Argentina, la escuela no está desarrollando adecuadamente su tarea formativa, ya que las diferentes evaluaciones que han realizado los organismos internacionales muestran retrocesos significativos en relación con los países de la región. Concuerdan con las últimas evaluaciones realizadas por el Ministerio de Educación de la Nación.

Ante este contexto, que evidentemente afecta a los alumnos de las escuelas de nivel medio, será necesario que las autoridades educativas reformulen la organización, los diseños curriculares y la gestión con un modelo de mayor participación, con formas de poder y resoluciones descentralizadas, y se inserten con mayor profundidad en la comunidad. La evaluación debe ser permanente, tanto de directivos como de docentes, del rendimiento escolar de Ios alumnos, y fundamentalmente con aulas abiertas, con creatividad y con propuestas que conduzcan a la innovación y el pensamiento crítico.

Finalmente, esta síntesis tiene que considerar la necesaria interacción interinstitucional con organizaciones económicas, artísticas, los deportes y otras escuelas, promoviendo una más profunda interacción social. Con esta actitud, también debe recomponerse la relación entre la escuela y la familia. En la actualidad, se sabe que no existe en el ámbito público una relación continuada y constructiva con los padres de los alumnos. Esta situación es más grave en las zonas carenciadas, donde habitan personas y grupos realmente vulnerables, sin educación básica; y desde hace años, de pobreza, con necesidades básicas insatisfechas, desocupación y abandono de las mínimas condiciones de higiene y ambientales. Son los más perjudicados de toda la sociedad.

Esta difícil situación no solo es un problema social, económico o político. Es una necesidad que debe tener una visión ética, donde los que son maestros, las autoridades, tienen la obligación de enseñar a mejorar los vínculos de todos, a ser mejores ciudadanos, a respetar las leyes, a observar las normas básicas de convivencia con valores que dignifiquen al ser humano en forma integral.

\section{La violencia}

Concurrentemente con el contexto iniciado anteriormente, el Barómetro del Narcotráfico y las Adicciones en la Argentina: serie del bicentenario 2010-2016: informe n. ${ }^{\circ}$, año $2017,{ }^{3}$ señala que "la seguridad es considerada como una de las necesidades básicas, siendo esencial para el bienestar y desarrollo de la persona". Por lo tanto, se considera que constituye una de las necesidades psicológicas fundamentales, que da impulso del organismo, que activa y orienta la conducta hacia ciertas metas, que al ser logradas posibilitan la supervivencia y bienestar, y una mejor salud. Recalca el informe $n .^{\circ} 3$ que el "impacto de ciertos hechos negativos, entre los que se encuentran ser testigo de hechos violentos o el haber sufrido experiencias traumáticas y de violencia, tendrán serías consecuencias y consecuencias graves sobre las personas que han sufrido violencia como también sus familiares".

Se destaca las consideraciones del Fondo de las Naciones Unidas para la Infancia (Unicef, siglas del inglés), ${ }^{4}$ que informan las dificultades para denunciar las situaciones pasadas o presentes de violencia debido a la vergüenza o bien al temor a posibles represalias. Resulta evidente, hoy, que existen verdaderamente ocasiones de

3 Barómetro del Narcotráfico y las Adicciones en la Argentina: serie del bicentenario 2010-2016: Informe n. ${ }^{\circ}$, año 2017: "Adicciones y vulnerabilidad social: el consumo problemático de alcohol, factores de riesgo, grupos vulnerables y consecuencias sociales" /Juan Ignacio Bonfiglio... [et al.]. Recuperado el 16 de febrero de 2018 de http://www.kas.de/wf/doc/24483-1442-1-30.pdf

4 Unicef Sección de Datos y Analítica División de Datos, Investigación y Políticas 3 United Nations Plaza Nueva York, NY 10017, EE.UU. Recuperado el 16 de febrero de 2018, de https://www.unicef.org/publications/files/Violence_in_the_lives_of_children_Key_findings_Sp.pdf 
impunidad de las personas que ejercen la violencia; y lo que resulta aún más grave, que las víctimas consideren que la violencia es normal.

Así se disimula la violencia, y no es posible entonces ni prevenirla ni eliminarla. Unicef señala la evidente escasez de datos objetivos, lo cual agrava este problema. "La recopilación de datos sobre la violencia contra los niños es una tarea compleja que presenta importantes problemas éticos y metodológicos."

Hoy la violencia en las vidas de los niños y de adolescentes permite inferir y determinar cuatro formas básicas de violencia: "La disciplina violenta y la exposición al maltrato doméstico durante la primera infancia; la violencia en la escuela; las muertes violentas entre los adolescentes; y la violencia sexual en la infancia y la adolescencia". Aquí ya se señalan ámbitos y enfoques para la investigación científica que, evidentemente, habrá que complementar con las realidades del contexto que se trate.

\section{Embarazo adolescente}

Los antecedentes en cuanto a los datos de estadísticas hospitalarias del Ministerio de Salud de la Nación ${ }^{5}$ sobre el sistema público de salud son los siguientes: en 2011 se registraron 47.879 egresos hospitalarios por aborto en Argentina, de los cuales el $19 \%$ correspondió a mujeres menores de 20 años. En 2012 murieron en Argentina 33 mujeres a causa de embarazos terminados en aborto; dos de ellas eran adolescentes menores de 20 años, y 7 , jóvenes de entre 20 y 24 años (DEIS, 2013). En 2013, el $50 \%$ de las muertes por embarazo terminado en aborto correspondió a mujeres de 15 a 29 años, entre ellas nueve de adolescentes de 15 a 19 años (DEIS, 2014). En un contexto que muestra una elevada proporción de partos ocurridos en instituciones de salud (99\%) y de partos atendidos por profesionales capacitados (98\%) (DEIS, 2013), la Argentina tiene el potencial necesario para disminuir considerablemente la tasa de mortalidad materna y las amplias brechas que existen en la materia. Sin embargo, las inequidades en el acceso a servicios, en la disponibilidad de recursos humanos y físicos adecuados y en la calidad de la atención sanitaria impactan de diferente forma sobre las razones de la mortalidad materna y generan un riesgo desproporcionado para las mujeres que viven en las jurisdicciones más pobres del país.

En la actualidad, el Plan Nacional de Prevención y Reducción del Embarazo no Intencional en la Adolescencia (20172019) 6 informa que el

$15 \%$ de los nacimientos (DEIS, 2015) que se produjeron en el año 2015 correspondió a madres adolescentes menores de 19 años, lo cual constituye un riesgo para la salud de esas madres adolescentes y un hecho que compromete enormemente sus trayectorias de vida y posibilidades de integración social a través del estudio o el trabajo. Este fenómeno se acrecienta cuando se observa la magnitud del embarazo no intencional: casi 7 de cada 10 adolescentes de entre 10 y 19 años que tuvo un hijo en 2015 y que no había buscado ese embarazo (SIP-G,2015).

Se estima que anualmente, en Argentina, se producen alrededor de 700.000 nacimientos, de los cuales 105.000 son de madres menores de 19 años. De ellos, el 70\% son embarazos no buscados, y ellos han motivado el abandono de la cursada en la escuela de nivel secundario, como también la pérdida de sus posibilidades laborales futuras y cuidar a otros niños de la familia.

Se encuentran abuelas de 35 años de edad, y que ciertos adolescentes llegarán a los 25 años con cuatro hijos.

Esta problemática, desde hace años, revela la ausencia del estado nacional como también a escala provincial y municipal. Argentina, al ser un país federal, no ha logrado instrumentar políticas de Estado en forma sistemática en esta y otras tantas problemáticas que afectan la salud y la situación social, política y económica. No obstante, se ha diseñado y comenzado a instrumentar el nuevo Plan Nacional de Prevención y Reducción del Embarazo no Intencional en la Adolescencia (2017-2019), que incluye el marco teórico, el diagnóstico, las estadísticas, las consideraciones legales y las propuestas de acción, como la asistencia técnica y el apoyo a las autoridades provinciales para la implementación de programas locales en todas las provincias; la distribución de materiales de comunicación a todas las jurisdicciones

\footnotetext{
5 Álvarez, A. Cattáneo, V. Musacchio, O. y Provenzano, B. (2015). "Protocolo para la atención integral de las personas con derecho a la interrupción legal del embarazo". Programa Nacional de Salud Sexual y Procreación Responsable. 2.a Ed. Buenos Aires.

6 Plan Nacional de Prevención y Reducción del Embarazo no Intencional en la Adolescencia (2017-2019). Recuperado el 16 de febrero de 2018 de https://www. argentina.gob.ar/sites/default/files/argentina._documento_plan_nacional_de_prevencion_y_reduccion_embarazo_no_intencional_en_la_adolescencia._vf.p df
} 
del país; la elaboración de actividades de capacitación a equipos de salud en las distintas jurisdicciones del país; la implementación de actividades de promoción comunitaria en las distintas jurisdicciones; la elaboración de materiales de comunicación y organización de campañas; y la sistematización de información estadística. Entre sus diversos objetivos, se resaltan los siguientes: a) disminuir la morbimortalidad materno-infantil, b) prevenir embarazos no deseados y c) promover la salud sexual de los adolescentes. Realizar estas actividades, son evidencias actuales de la deuda social que existe en los últimos 30 años en Argentina.

\section{Las adicciones}

Como introducción, el Barómetro del Narcotráfico y las Adicciones en la Argentina 20177 señala uno de los principales objetivos que se debe considerar, y explica que "la información científica y la demanda social vienen persuadiendo acerca de focalizar la atención en el consumo de alcohol, ya sea por la baja en la edad de inicio, por la frecuencia, por la alta incidencia de ingestas abusivas en población joven o cambios en los hábitos de consumo de bebidas alcohólicas".

El consumo de alcohol ha generado la atención en la salud pública, ya que esta droga es una de las principales causas de muerte, además de promover enfermedades y discapacidades, en tanto que su ingesta está ampliamente relacionada con las lesiones por causas externas. Pero también es pertinente señalar que los riesgos son diferentes en lo individual y a escala comunitaria.

Considerando los aportes sistemáticos del Barómetro del Narcotráfico y las Adicciones en la Argentina, 8 pueden inferirse, en cuanto a este flagelo y esta epidemia, diversos factores relevantes que se sintetizarán a continuación: en cuanto a los factores individuales, 9 se sabe que durante muchos años los estudios realizados informan resultados consistentes respecto a las características sobre la personalidad que facilitan la comprensión en cuanto al consumo de alcohol en la población joven. Entre estas características "se destaca por su capacidad explicativa la búsqueda de sensaciones, definida como la necesidad de experiencias variadas, novedosas, intensas y complejas, y una tendencia a involucrarse en situaciones de riesgo para lograr tales experiencias" (Zuckerman, 2007).

Otras situaciones se relacionan con comportamientos más perjudiciales en la población joven, como la desinhibición conductual y la búsqueda de experiencias sensoriales fuertes. Luego, en otro orden, se observa el deseo de lograr estimulación mediante deportes y actividades de mediano o alto riesgo, generalmente planificadas.

Quizás, el consumo excesivo para los adolescentes les posibilita percepciones positivas sobre sí mismos, independientemente de conocer las evidencias de las consecuencias negativas ya científicamente determinadas respecto del consumo de alcohol y otras sustancias en la adolescencia. En cuanto a las adicciones, se dispone de otros trabajos de investigación, entre los cuales se encuentra "Consumo riesgoso de alcohol en población joven y factores asociados. Línea de investigación-acción con jóvenes escolarizados del área metropolitana bonaerense". ${ }^{10}$

En el citado trabajo se resalta que "la investigación en consumo de alcohol es hoy una tarea básica necesaria para el diseño de políticas públicas efectivas capaces de abordar una problemática que es alarmante en todo el territorio nacional". Posteriormente se señala que el consumo de alcohol aumentó en los últimos años y que cada vez más mujeres consumen sustancias y alcohol, y cada vez se consume a edades más tempranas, de acuerdo con la Organización Panamericana de la Salud (OPS, 2015) y la Secretaría de Políticas Integrales sobre Drogas de la Nación Argentina (Sedronar, 2017). Los niveles más altos de consumo se observan en jóvenes de 16 a 24 años (Observatorio Argentino de Drogas,2014).

7 Barómetro del Narcotráfico y las Adicciones en la Argentina. Recuperado el 16 de febrero de 2018 de https://www.researchgate.net/publication/324213232_ BAROMETRO_DEL_NARCOTRAFICO_Y_LAS_ADICCIONES_EN_LA_ARGENTINA,p. 7.

8 Barómetro del Narcotráfico y las Adicciones en la Argentina: serie del bicentenario 2010-2016: Informe n. ${ }^{\circ}$, año 2017: "Adicciones y vulnerabilidad social: el consumo problemático de alcohol, factores de riesgo, grupos vulnerables y consecuencias sociales" / Juan Ignacio Bonfiglio... [et al.] Recuperado el 16 de febrero de 2018 de http://wadmin.uca.edu.ar/public/ckeditor/2017-Observatorio-barometro_NyA_N4.pdf

9 Schmidt, V.; Molina, M.F.; Raimundi, M.J.; González, M.A.; Di Puglia, G. y Celsi, I. "Investigaciones queaportan al Estado de Situación del consumo de alcohol en la Argentina".Conicet - UBA - UAl. Barómetro del Narcotráfico y las Adicciones en la Argentina |n. ${ }^{\circ} 4 / 2017$. Recuperado el 16 de febrero de $2018 \mathrm{de}$ http:// wadmin.uca.edu.ar/public/ckeditor/2017-Observatorio-barometro_NyA_N4.pd

10 Ibídem Pág. 32. 
El 50\% de los adolescentes de 12 a 17 años probó alcohol en el último mes, y, entre ellos, 1 de cada2 lo hizo de forma abusiva. A su vez, se ha registrado un aumento de nuevos consumidores preadolescentes y adolescentes en el último año y se ha constatado un aumento del consumo abusivo.

El Barómetro del Narcotráfico y las Adicciones en la Argentina, de la Universidad Católica Argentina, informa que la mayor vulnerabilidad de los jóvenes frente al narcotráfico y las drogas se produce en los barrios con contexto de mayor exclusión social y ausen cia de un Estado protector. El aumento no solo es en cuanto a consumo, sino que también incluye el tráfico y producción de diferentes tipos de drogas (pasta base). ${ }^{11}$

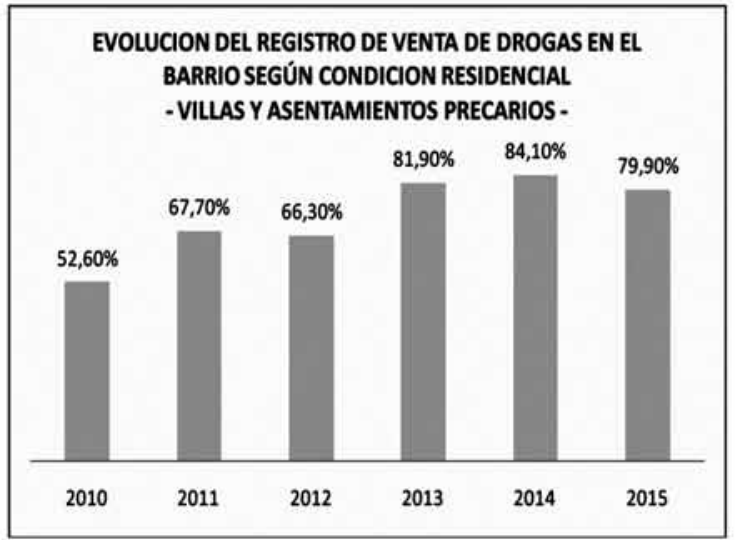

Desarrollo de trabajos prácticos individuales y en grupos en la escuela

La Dirección General de Cultura y Educación, Subsecretaría de Educación, Provincia de Buenos Aires (2008) proporciona el diseño curricular de la asignatura Construcción Ciudadana, para el nivel secundario, $1 \mathrm{er}, 2 .^{\circ}$ y $3 e r$ año, ${ }^{12}$ que posee numerosos detalles pedagógicos y didácticos debidamente fundamentados para la elaboración de las clases, promoviendo la participación intensa entre docentes y alumnos, y especificando cómo elaborar los trabajos prácticos. En tal sentido, se tiene en consideración la siguiente premisa:

Es una materia donde se parte de intereses/temas/problemas que identifican y definen los jóvenes, para comprender y aprender cómo éstos se relacionan con los contextos socioculturales en los que se producen y desarrollan, y especialmente, cómo es posible intervenir en ellos (mediante la capacidad de hacer que todos tienen) a partir del ejercicio de prácticas de ciudadanía.

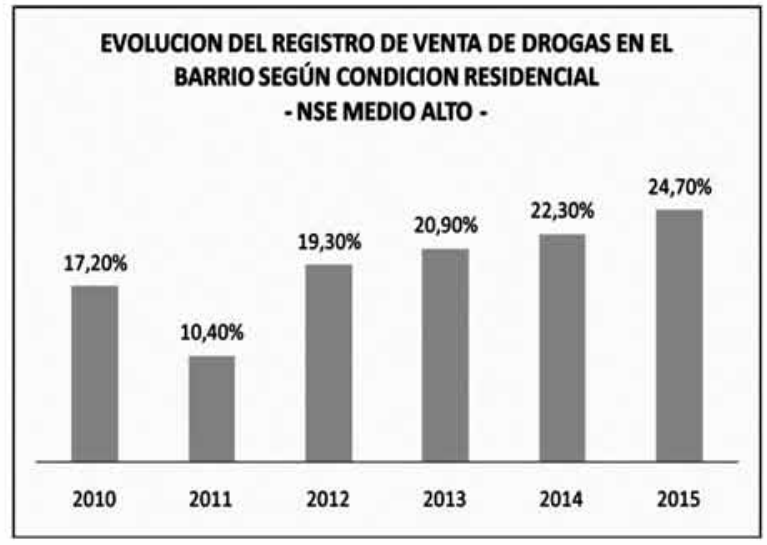

Esta decisión educativa es esencial, y sobre esta base se pueden elaborar los proyectos. Se establecen las etapas clave para asegurar su mejor presentación y desarrollo, donde el alumno debe trabajar en íntima relación de lo que ocurre en su barrio, sus necesidades, y pensar cómo elaborar propuestas creativas para minimizar las consecuencias negativas de ellas. Entre los proyectosque se han de elaborar se señalan los siguientes: "Campaña comunicacional sobre $\mathrm{VIH} / \mathrm{Sida}$ (p. 91), c: "El periódico y la radio locales" (p. 93), D: "¿Qué dicen los medios?" (p. 94), a: "Seguridad" (p. 112), d: "Somos del barrio" (p. 130), b."Proyecto de deporte para todos" (p. 142), c. "Drogas" (p. 162). No se consideran en forma específica los temas relacionados con el embarazo adolescente.

El equipo directivo debe supervisar y acompañar la tarea docente, ${ }^{13}$ ya que es parte constitutiva de su función, como en el resto de las materias. En el caso de la asignatura Construcción de Ciudadanía, el diseño curricular provee herramientas que pueden ser de gran utilidad para esta tarea: las expectativas de logro de enseñanza y de

11 Bonfiglio, J.I. Barómetro del Narcotráfico y las Adicciones en la Argentina: serie del Bicentenario 2010-2916: Informe n. ${ }^{\circ}$. 2016, p. 23. Recuperado el 16 de febrero de 2018de http://www.kas.de/wf/doc/24483-1442-1-30.pdf

12 Diseño curricular para la Escuela Secundaria. Construcción de ciudadanía. 1era 3er año. (2007) Dirección General de Cultura y Educación, Subsecretaría de Educación. Provincia de Buenos Aires Recuperado el 27 de febrero de 2018 de http://servicios.abc.gov.ar/lainstitucion/organismos/consejogeneral/disenioscurriculares/documentosdescarga/secundariaciudadania.pdf

13 Ibídem. P.3. 
aprendizaje, que además se encuentran vinculadas con un cuadro de correspondencia entre logros de enseñanza y logros de aprendizaje. Las bases, pese a los años transcurridos, son totalmente suficientes para su exitoso desarrollo. Sí, se comprueba en las entrevistas desarrolladas durante el trabajo de campo que los alumnos, e incluso sus familiares, no han internalizado ni recuerdan, salvo escasas excepciones, los temas dictados en esta asignatura.

\section{Los medios de comunicación social. El celular}

Son valiosos los aportes de Gómez-Escalonilla Lorenzo (2017), ${ }^{14}$ en su análisis de diversas publicaciones y trabajos de investigación, sobre la influencia de los "medios de comunicación y consumo de drogas en la adolescencia". Gómez-Escalonilla, ha evaluado publicaciones científicas en buscadores y bases de datos; entre ellas, menciona Pubmed, Dialnet, IME, Cuiden, Medes y Enfispo. Al respecto, se efectuarán referencias de parte de los hallazgos relevantes y que por su generalización pueden ser realmente aplicados a nuestro país y América Latina.

El primer aspecto fundamental es tomar conciencia de que, en las adicciones y otras problemáticas de los adolescentes, los medios de comunicación

tienen en nuestra sociedad un papel fundamental como agentes de socialización y de transmisión de cultura, conocimientos y valores. Diversos estudios señalan que, en el caso de los menores de edad, los medios de comunicación influyen en su educación tanto como la escuela y la familia. El entorno familiar ha pasado a ser considerado el segundo agente de socialización, por detrás de los medios e igualando a la propia escuela. ${ }^{15}$

Efectivamente, impactan en forma sistemática y con profundidad influyendo decididamente en la conciencia de los niños mediante la televisión, internet, los portales sociales e informativos, ya al alcance de todos los niños y jóvenes con su teléfono celular. Los contactos diarios se miden en millones.
Posteriormente, se citan otros datos relevantes encontrados en los estudios sobre la influencia de los medios de comunicación en los adolescentes, que refieren los siguientes conceptos claves; que el "consumo de drogas se presenta con frecuencia desde una perspectiva de diversión, dinero fácil, conducta de los famosos, etc., sin realizar referencias críticas a este estilo de vida". Se señala que "en muchos medios de comunicación, el tabaco, el alcohol y los fármacos no son considerados drogas o se banalizan sus riesgos, lo que hace necesario redefinir desde una perspectiva informativa el concepto de droga, para poder ir mucho más allá de la condición de la legalidad de las sustancias, su uso o su procedencia".

Así, se exponen conceptos como "son modelos de conducta no saludable con ausencia de riesgo", "imagen glamurizada que vincula el consumo con resultados positivos", "presencia de contenidos que exageran la prevalencia de algunas drogas en la vida diaria". Es obvio que este aspecto genera en el adolescente la percepción de que consumir es un comportamiento normal y habitual. "Falta de especialización, que aporta una perspectiva de la noticia de personas que no dominan el contexto de la información, con la falta de rigor que esto puede suponer en su contenido...".16 Se observa a diario, en las noticias, el desconocimiento de la problemática y la falta de profundidad de su tratamiento, incluso considerando las sustancias como poco peligrosas para la salud de las personas.

Otro de los aspectos observados es el error de "no adoptar un enfoque constructivo del problema, para tratar de informar sobre los efectos negativos de las drogas y sobre las actuaciones que realizan las instituciones para prevenir y tratar el consumo". No solo se considera en forma errónea los temas adicciones, violencia, bullyng, grooming, embarazo no intencional, así como el del déficit de la escuela secundaria, que es comunicado negativamente provocando falsas imágenes, conceptos equivocados, facilismo y abandono de valores y conductas acordes con los derechos y obligaciones de las personas para con la

14 Gómez-Escalonilla Lorenzo. “Medios de comunicación y consumo de drogas en la adolescencia”. Recuperado el 27 de febrero de 2018 de http://publicacionesdidacticas.com/hemeroteca/articulo/080064/articulo-pd

15 Ibídem, p.372.

16 Ibídem, p.373. 
sociedad. Si se tiene en cuenta que en Argentina viven 13 millones de niños, niñas y adolescentes; y que 6 de cada 10 se comunican utilizando celular; y que 8 de cada10 utilizan internet, ${ }^{17}$ se repara en los datos proporcionados por la Encuesta Nacional sobre Acceso y Uso de Tecnologías de la Información y la Comunicación, ${ }^{18}$ que informaba ya en el año 2011 que el 59,4 \% de los niños, niñas y adolescentes del grupo de edad entre 10 y 19 años utilizaban el celular, y que el $77,8 \%$ ya empleaba internet, debe recordarse y comprenderse que los medios masivos de comunicación se constituyen hoy en agentes socializadores con una enorme influencia en la formación de identidades juveniles, incluso remplazando en buena medida otras formas de socialización, como la familia y la escuela.

\section{Estudiar y capacitarse para el trabajo futuro}

Muy especialmente, los directivos y docentes en las escuelas secundarias deben tener presente este concepto que con un sentido ético obliga a trabajar mucho más, y en mayor profundidad con personas carenciadas. El diseño curricular de la asignatura Construcción de ciudadanía ${ }^{19}$ afirma que "los problemas en el mercado de trabajo no afectan a todos por igual. Cuando el mercado de trabajo se deteriora las consecuencias más severas las sufren quienes tienen menor capital educativo, ya que es muy común que se exijan determinadas capacidades educativas para puestos que antes no las requerían" (Miranda, Otero, 2002). Es por ello que las personas con menor nivel de escolarización quedan más relegadas a empleos en el segmento secundario, precario, de indigencia o asistido por planes, o desempleados.

Luego cita a Jacinto et al, cuyo párrafo mantiene plena actualidad y afirmaciones que se agravan, que señala que en

el contexto actual de profundas transformaciones económicas y productivas, miles de jóvenes encuentran muchas dificultades para ingresar al mercado de empleo, ya que tienen que encontrar puestos vacantes en un mercado laboral que no genera cuantitativamente dichas oportunidades para las nuevas generaciones (Jacinto, Lasida, Ruégalo, Berruti, s.f).
Al respecto, el diseño curricular no proporciona objetivos ni estrategias educativas ni de acción, para el mejor desarrollo de clases que motiven a los estudiantes a imaginar y pensar su proyecto de vida y su futuro, con la profundidad que estas decisiones requieren.

En la actualidad, en parte se ha avanzado, y la provincia de Buenos Aires, mediante Consejo Provincial de Educación y Trabajo, de la Dirección General de Cultura y Educación, ${ }^{20}$ profundiza en la mejora de la articulación del nivel secundario con el superior y con el mundo laboral. Así, los estudiantes tienen la posibilidad de conocerse a sí mismos, y de este modo acercarse a la mejor toma de decisiones en su tránsito hacia los estudios superiores. Desde el municipio se crea la Secretaría de la Mujer, Niñez y Adolescencia, para el abordaje integral de la problemática adolescente. Asimismo, se cuenta con la Escuela de Oficios, con el objetivo de capacitarlos para el futuro.

La decisión de continuar sus estudios constituye un momento muy importante en la vida de los jóvenes. Y es un proceso que incluye muchas variables que se deben tener en cuenta, como las características de personalidad, sus aptitudes y habilidades, sus motivaciones, el tiempo de dedicación a la carrera, o las posibilidades reales de inserción laboral luego del egreso, entre otras. El ámbito laboral será cada vez más exigente.

La web cuenta con un cuestionario de intereses, una técnica psicopedagógica utilizada habitualmente, y que es tomada como un instrumento diseñado para evaluar intereses asociados con diferentes alternativas educacionales.

\section{Metodología}

En cuanto al enfoque, esta investigación será de carácter exploratorio, que se caracteriza por ser aquella realizada en áreas y problemas de los cuales hay escaso o nulo conocimiento acumulado y sistematizado. Por la naturaleza del sondeo, no partirá de hipótesis. Ellas podrán surgir como producto final de la investigación. En otro orden, se deberá hacer un gran esfuerzo por sistematizar los datos que se

17 Paolini, P. y Ravalli, M.G.(2016)KIDS ONLINE.chic@sconectados. Investigación sobre percepciones y hábitos de niños, niñas y adolescentes en internet y redes sociales. Fondo de las Naciones Unidas para la Infancia (Unicef). Recuperado el 27 de febrero de 2018, de http://www.indec.gov.ar/bajarlnformedePrensa.asp?idc=37DB4687D3BACB32F229C4E7B42BE5762941FE2 C6BE449291FEFF313D51211CA9FEFF0FD2338BC1E

18 Ibídem, p. 6.

19 Dirección General de Cultura y Educación. “Diseño curricular asignatura construcción de ciudadanía" (2007) Recuperado el 27 de febrero de 2018 de http:// servicios.abc.gov.ar/lainstitucion/organismos/consejogeneral/disenioscurriculares/documentosdescarga/s ecundariaciudadania.pdf

20 Consejo Provincial de Educación y Trabajo de la Dirección General de Cultura y Educación.

"Objetivos". Recuperado el 27 de febrero de 2018 de http://www.abc.gov.ar/se-lanz\%C3\%B3- clique\%C3\%A1-tu-futuro 
vayan recolectando, por priorizar y definir la incumbencia de la información.

El presente trabajo de investigación tendrá un enfoque mixto, de acuerdo con Hernández Sampieri (2014), ${ }^{21}$ que expone: "El enfoque mixto surge como consecuencia de la necesidad de afrontar la complejidad de los problemas de investigación planteados en todas las ciencias y de enfocarlos holísticamente, de manera integral". Ya en 1973, Sam Sieber (citado por Creswell, 2005) sugirió la combinación de estudios de caso cualitativos con encuestas, creando "un nuevo estilo de investigación" y la integración de distintas técnicas en un mismo estudio.

Luego, Hernández Sampieri, señala: "Los métodos mixtos no nos proveen de soluciones perfectas; sin embargo, hasta hoy, son la mejor alternativa para indagar científicamente cualquier problema de investigación. Conjuntan información cuantitativa y cualitativa, y la convierten en conocimiento sustantivo y profundo". Puede agregarse que el enfoque mixto tomará lo mejor de lo cuantitativo y cualitativo sin desmerecer a ambos enfoques.

\section{Investigación en la educación}

Desde la educación, además de lo que debe ocurrir hoy en las aulas, y que se está transformando sustancialmente, debemos pensar y aplicar, en cuanto a la metodología de la investigación, la concepción constructivista que expone Hernández Sampieri, y que fue promovida por "Jean Piaget (1896-1980) y Lev Semenovich Vygotsky (1896-1934) en la Educación y John Dewey (1859-1952) en la Pedagogía; así como Margaret Mead (1901-1978) en la Antropología".

“El constructivismo como uno de los 'padres' del enfoque cualitativo le otorga los énfasis principales que lo caracterizan, entre ellos, el reconocimiento de que el investigador necesita encuadrar en los estudios los puntos de vista de los participantes." Aquí es necesario indagar las cuestiones abiertas; será fundamental conocer el contexto cultural, los datos deben recolectarse en los lugares donde realmente las personas realizan sus actividades cotidianas, es decir, la escuela y su entorno.
La investigación debe, necesariamente, ser útil para mejorar la forma en que viven las personas, promoviendo mejoras. Se estudian conceptos, cuya esencia no solamente se captura por medio de mediciones y considerando las siguientes dimensiones: tratamiento de los problemas en la escuela, prevención de la violencia, embarazo adolescente, prevención sobre la toma de alcohol y drogas, realización sobre la problemática de trabajos prácticos individuales o grupales, influencia de la propaganda y los medios de comunicación, la importancia del trabajo y los estudios para el futuro.

\section{La investigación cualitativa en salud}

\section{Manuel Amescua y Alberto Gálvez Toro ${ }^{22}$ afirman que}

El interés en el análisis cualitativo en el contexto de las ciencias de la salud se ha producido a partir del interés demostrado por los investigadores sociales en las instituciones sanitarias [...] estudios como los de Goffman sobre hospitales psiquiátricos y su concepto de institución total alertaron aunque tardíamente, sobre la necesidad de abordar determinados problemas de salud desde perspectivas bien distintas a las puramente biomédicas, perspectivas que admiten la subjetividad, tanto de los sujetos investigados como del investigador.

Luego refieren que, en este contexto de la salud, se abren espacios multidisciplinarios, donde será necesario que participen todos los integrantes del equipo de salud, y que muy lejos de ser un inconveniente serán aportes de alto valor para la producción científica. Posteriormente, señalan que cuando el investigador se dirige a los "problemas de salud en su dimensión social o cultural (concepciones y representaciones, política, administración, instituciones, etc.) los modos de análisis basados en la estadística se quedan así siempre estrechos y comienza la búsqueda de instrumentos metodológicos más flexibles...". ${ }^{23}$

Diversos autores, entre ellos Bardin, ${ }^{24}$ consideran que la investigación cualitativa tiene tres principales finalidades: la primera, la búsqueda del significado de los fenómenos a partir de los datos concretos, la segunda, confirmar o rechazar hipótesis, y la tercera, ampliar la comprensión de la

21 Hernández Sampier, R. et al. (2014). Metodología de la Investigación Científica. 6.a Ed. "Profundización en temáticas de la investigación cualitativa". Centro de recursos. Recuperado el 27 de febrero de $2018 \mathrm{de} \mathrm{http//www.mhhe.com/he/hmi6e}$

22 Amescua, M. y Gálvez Toro, A. (2002). "Los Modos de Análisis en Investigación en Salud: Revista Españolade Salud Pública". V.76, n. 5, Madrid,Set.-Oct.,p. 3. Recuperado el 27 de febrero de 2018 de http://scielo.isciii.es/scielo.php?script=sci_arttext\&pid=S1135-57272002000500005

23 Ibídem.P.3.

24 Bardin, L. (1979).Análise de Conteúdo. Lisboa: Ediçoes 70. 
realidad como una totalidad. Esta última finalidad es la que se tratará de mostrar en el presente trabajo de investigación cualitativa y realmente mixta.

Aquí, otra de las decisiones trascendentes será la de determinar qué tipo de análisis cualitativo se aplicará para considerar los centros de salud y conocer parcialmente qué ocurre en su íntimo y profundo interior. Para ello, se destacan los aportes de Barton y Lazarsfeld, que proponen identificar cinco niveles en los procedimientos de análisis del material cualitativo en funciónde su complejidad: las simples observaciones, la construcción o aplicación de sistemas descriptivos (listas y tipologías), las relaciones entre variables, las formulaciones matriciales y el apoyo cualitativo en la formulación de teoría. ${ }^{25}$ Pues, en el presente trabajo, se partirá de la observación y la utilización de encuestas elaboradas y ya validadas por diversos equipos de trabajo con un enfoque multidisciplinario, sin exclusiones.

Puede apreciarse, aún más, la conveniencia de utilizar este procedimiento para la recolección de datos en instituciones que, como el hospital o un centro de salud, se desarrollan actividades profesionales altamente relacionadas con la comunidad, y cuyas estadísticas refieren del alivio, el sufrimiento y la preservación de la salud y la vida de las personas, en un marco académico y científico con condiciones difíciles en lo social, pero generalmente en un ámbito contenedor, afectivo y humano.

En relación con el universo y la muestra, debe considerarse la amplia extensión del partido de Malvinas Argentinas. Al respecto, se comenzará a indagar qué ocurre con los adolescentes, tanto desde la escuela pública como la salud pública, en sus problemáticas más conflictivas y que mayor daño hacen a este grupo etario y a la comunidad toda.

Se considerarán, como muestra, a 7 centros de salud y unidades funcionales y alumnos de escuelas públicas de sectores carenciados.
Los instrumentos de recolección de datos estarán constituidos por dos encuestas semiestructuradas y entrevistas para conocer con el mayor detalle las vivencias actuales de los adolescentes de una zona carenciada, en el partido de Malvinas Argentinas. Los datos obtenidos serán analizados mediante el software SPSS 15.0 y ATLAS.ti 8 . Los gráficos que se presentan son de elaboración propia y realizados de acuerdo con los datos extraídos mediante encuestas y entrevistas desarrolladas por los investigadores y procesadas por programas informáticos y analizadas por profesionales expertos en Estadística Aplicada en Sistemas de Salud. Se han determinado como criterios de inclusión a los adolescentes con edades de 12 a 18 años.

\section{El contexto donde se ha desarrollado el trabajo decampo}

El sistema de salud del partido de Malvinas Argentinas cuenta con 13 hospitales de alta complejidad, que se financian con recursos provinciales (coparticipación), recursos municipales y con recursos privados mediante el cobro a pacientes de obras sociales y pacientes particulares.

El municipio cuenta además con atención primaria de la salud con 32 unidades funcionales, de las cuales 27 funcionan 8 horas, y 3,24 horas. Estas son atendidas por pediatras, médicos de familia, trabajadoras sociales, enfermeras y administrativas. Cuenta con vacunatorio (Plan Nacional de Vacunación), farmacias (Plan "Remediar"), métodos de anticoncepción (Programa Nacional de Salud Reproductiva y Procreación Responsable) y provisión de leche hasta los 2 años de vida, y el Programa de Epilepsia de la Provincia de Buenos Aires, que provee de anticonvulsivos.

Se destaca el sistema de salud del partido de Malvinas Argentinas, que ha distribuido en sus zonas críticas los centros de salud y unidades funcionales para mejorar la accesibilidad de las personas más vulnerables, favoreciendo la pronta atención y eventual derivación a centro de mayor complejidad.

25 Barton,A.H., Lazarsfeld, P.F. (1961). "Some functions of Qualitative Analysis in Social Research". En Lipset, S.M.y Smelser, N.J. (eds). Sociology: The Progress of a Decade. Englewwood-Cliffs: Prentice-Hall,pp. 95-122. 
El contexto en las unidades funcionales analizadas

\begin{tabular}{|l|l|c|}
\hline \multicolumn{1}{|c|}{$\begin{array}{c}\text { ESTABLECIMIENTOS } \\
\text { DE SALUD }\end{array}$} & \multicolumn{1}{c|}{ UBICACIÓN } & BARRIO \\
\hline $\begin{array}{l}\text { Unidad Funcional } \\
\text { "Grand Bourg Sur" }\end{array}$ & Calles Chacabuco y Luis Vernet & Grand Bourg 2 \\
\hline $\begin{array}{l}\text { Unidad Funcional } \\
\text { "El Camino" }\end{array}$ & Calles Wilde y Asamblea & Grand Bourg 1 \\
\hline $\begin{array}{l}\text { Unidad Funcional } \\
\text { "Ampliación Devoto" }\end{array}$ & Calles Paso de los Patos y Mario Bravo & Grand Bourg 3 \\
\hline $\begin{array}{l}\text { Unidad Funcional } \\
\text { "El Sol" }\end{array}$ & Calles Mahatma Gandhy y San Martín & Los Polvorines 3 \\
\hline $\begin{array}{l}\text { Unidad Funcional } \\
\text { "Unión y Progreso" }\end{array}$ & Calles Cerrito n. ${ }^{\circ}$ 506 y Dante Alighieri & Los Polvorines 3 \\
\hline $\begin{array}{l}\text { Unidad Funcional } \\
\text { "Magdalena" }\end{array}$ & Calles San Ignacio n. ${ }^{\circ}$ 1461 y Cerrito B ${ }^{\circ}$ Magdalena & Los Polvorines 2 \\
\hline $\begin{array}{l}\text { Unidad Funcional } \\
\text { "Villa Mayo" }\end{array}$ & Calles Eva Perón e/Arquímedes y Sucre & Villa Mayo 1 \\
\hline
\end{tabular}

Nota: se incluyen, como Anexo I., fotografías de las unidades funcionales involucradas, y como Anexo II., mapa de la sección del partido Malvinas Argentinas donde se realizó el trabajo de investigación.

\section{Breve descripción}

Con la finalidad de conocer aún más el contexto y poder caracterizar la infraestructura y configuración urbanas de la región seleccionada del partido de Malvinas Argentinas, distante a $35 \mathrm{~km}$ de la Ciudad de Buenos Aires, se debe establecer su ubicación donde se destaca al norte del sector, la traza del Ferrocarril General Manuel Belgrano Norte, que atraviesa de este a oeste toda la extensión del partido, contando con siete estaciones, y constituyendo el eje que vertebra y comunica a las localidades de mayor densidad poblacional. Hacia el sur, se encuentra la Ruta Nacional n. ${ }^{\circ} 8$, que la separa del partido de José $C$. Paz. Al este, su límite es la Ruta Nacional n. ${ }^{\circ} 202$.

La infraestructura y situación urbana es muy similar en todos los partidos que conforman el área metropolitana de Buenos Aires (Amba), y que rodean a la Ciudad Autónoma de Buenos Aires, cuando se consideran las zonas más carenciadas.

Al respecto, será necesario analizar las siguientes dimensiones básicas: agua potable, cloacas, desagües, gas, electricidad y transporte, para finalmente realizar una breve descripción de los habitantes próximos a las escuelas y unidades funcionales dónde se ha desarrollado este trabajo de investigación.
Así, en las unidades funcionales "Grand Bourg Sur", del barrio Grand Bourg 2, y la Unidad Funcional "Villa de Mayo", ubicada en el barrio Villa de Mayo 1, se encuentran las zonas mejor organizadas, donde la mayoría de las viviendas poseen agua de consumo seguro, cloacas, gas natural, electricidad y servicios de transporte públicos, como el tren y diversas empresas de ómnibus con recorridos urbanos.

En el barrio Grand Bourg 1, se comprueban tres sectores y asentamientos muy precarios, con casas construidas de ladrillos, maderas, cartones y plásticos, techos de chapa, algunos basurales, autos desarmados y abandonados, terrenos baldíos y corrales con caballos que inclusive circulan por las calles de tierra o pavimentadas.

En las otras cinco unidades funcionales - "El Camino", "El Sol", "Unión y Progreso", "Magdalena" y "Villa Mayo"—, se observan un $30 \%$ de viviendas de material, incompletas y precarias, agua de consumo no seguro al ser obtenida por perforaciones, pozos y cisternas. En cuanto a la provisión de gas natural, existe una red que une el $52 \%$ de todo el partido de Malvinas Argentinas; y el $48 \%$ restante utiliza gas engarrafas.

En un $30 \%$ las calles son de tierra con zanjas, y otros sectores requieren mantenimiento y saneamiento ambiental. Entre las unidades funcionales "El Sol" y "Unión y Progreso", 
ubicadas en el barrio Los Polvorines 1 y 2, se encuentran otras tres zonas con construcción de viviendas muy precarias, que no disponen de los servicios esenciales y básicos.

La población de la zona seleccionada está conformada por profesionales, técnicos, empleados del ámbito comercial, estudiantes y, en gran parte, trabajadores sin regularizar que viven de trabajos temporales, desempleados, y muchos de los cuales tienen planes sociales. En general se caracterizan por su adhesión al trabajo, la búsqueda de oportunidades de mejoras tanto en lo personal como en lo económico y social. No obstante, existen personas y grupos vulnerables en todos los grupos etarios, a consecuencias de la falta de una adecuada educación, el trabajo precario, la ausencia de trabajo y a que han sufrido las consecuencias del cierre de empresas industriales, comerciales y pymes por las crisis recurrentes en los últimos 30 años.

\section{Resultados}

1. Desde el punto de vista de la educación

\subsection{Tratamiento de los problemas en la escuela}

Se realizó un análisis y procesamiento de 60 entrevistas estructuradas. El análisis cualitativo se desarrolló sobre la base de dimensiones clave, complementándose con información cuantitativa para enriquecer la potencialidad de la información obtenida.

Respecto al tratamiento de los problemas en la escuela, podemos ver en el cuadroque se encuentra a continuación que el $76 \%$ de los estudiantes responden afirmativamente. El tratamiento de problemas suele ser por parte de directivos en los casos de situaciones puntuales que trascienden el aula. El tratamiento cotidiano de problemas es más reducido, y suele estar a cargo de algún preceptor o docente de alguna materia en particular. No se identifica el tratamiento de problemas incorporado a los procesos deenseñanza.

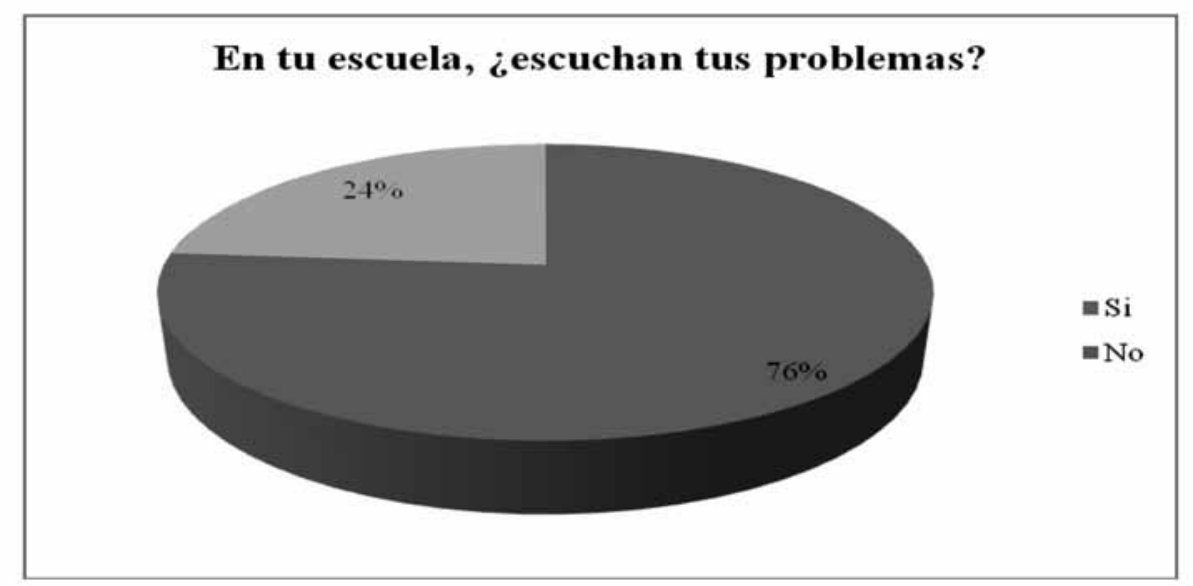


1.2 En tu escuela, ¿se habla y previene la violencia?

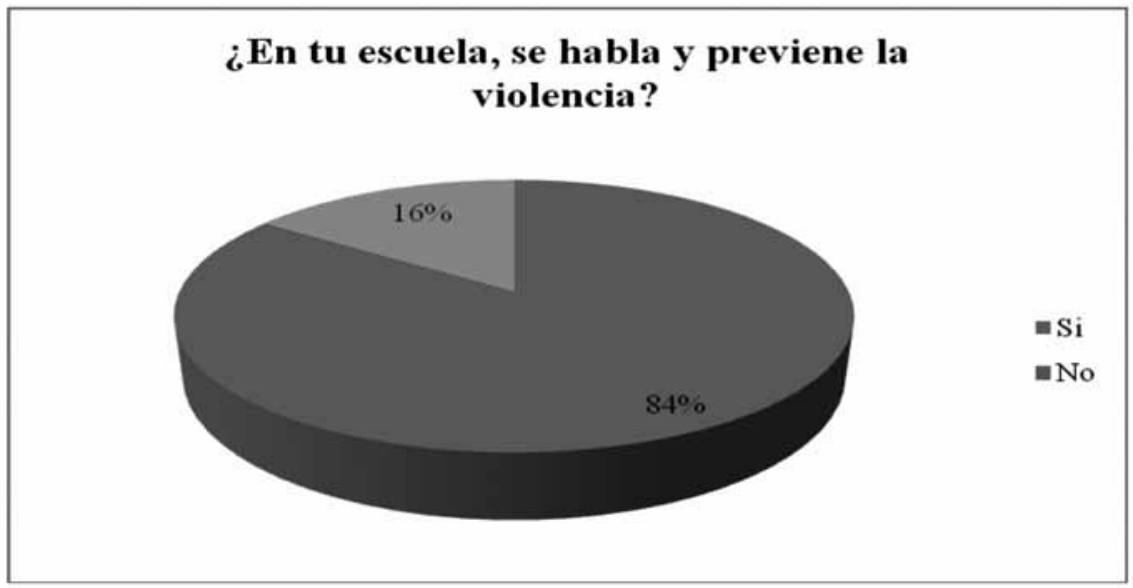

En cuanto al abordaje de la violencia, el $84 \%$ de los estudiantes afirman tratar el tema en la escuela. Dentro de ese porcentaje, el $38 \%$ refiere que hablan sobre problemáticas de violencia cuando suceden en el marco de la escuela. Esto tiene que ver con peleas entre estudiantes, faltas de respeto hacia docentes, y bullyng en un $12 \%$. Un $8 \%$ expresa recibir charlas cuando ocurre algún hecho que consideran relevante a nivel social: puede ser en el barrio o una situación de público conocimiento; y un $15 \%$ por violencia de género, también a causa del algún hecho conocido periodísticamente.

Estas cifras dan cuenta de que casi el 75 \% de los estudiantes que reciben prevención sobre problemáticas relacionadas con la violencia la reciben una vez que sucedió algún hecho, ya sea dentro o fuera de la escuela.

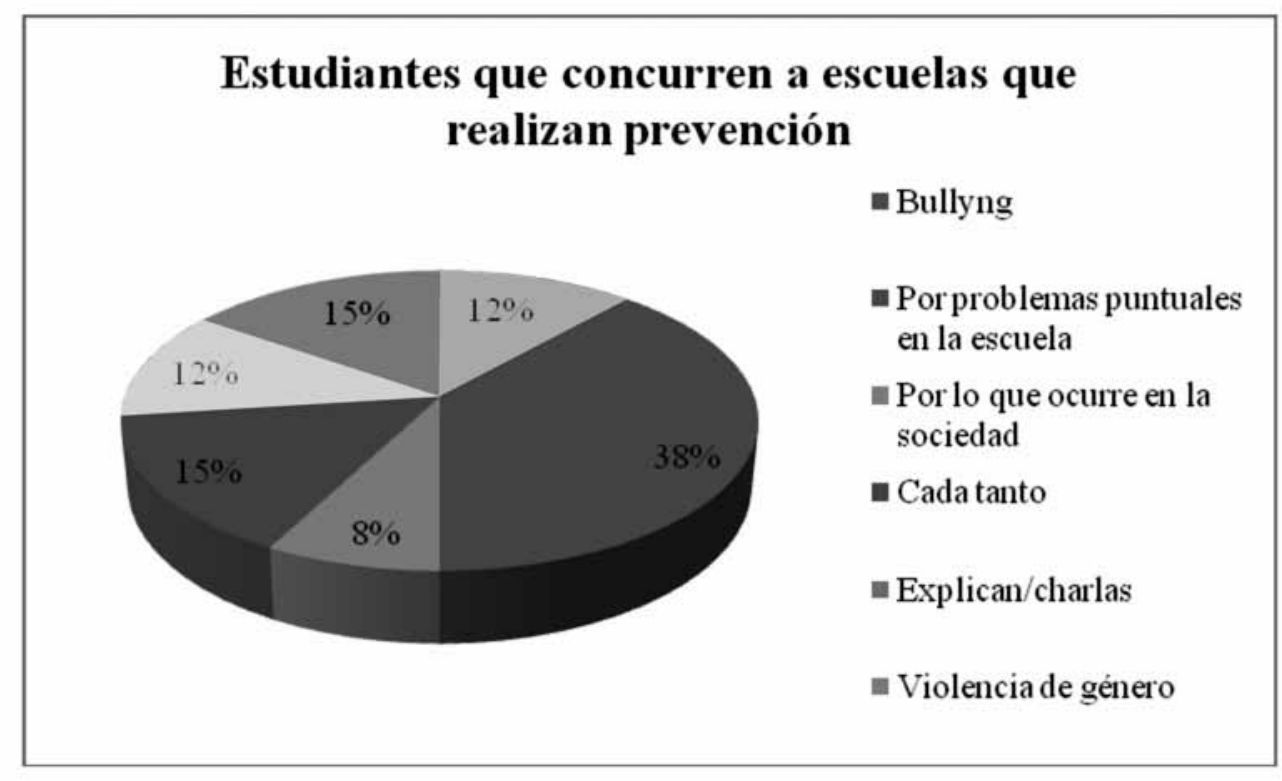


1.3 ¿Se habla en relación con el embarazo adolescente?

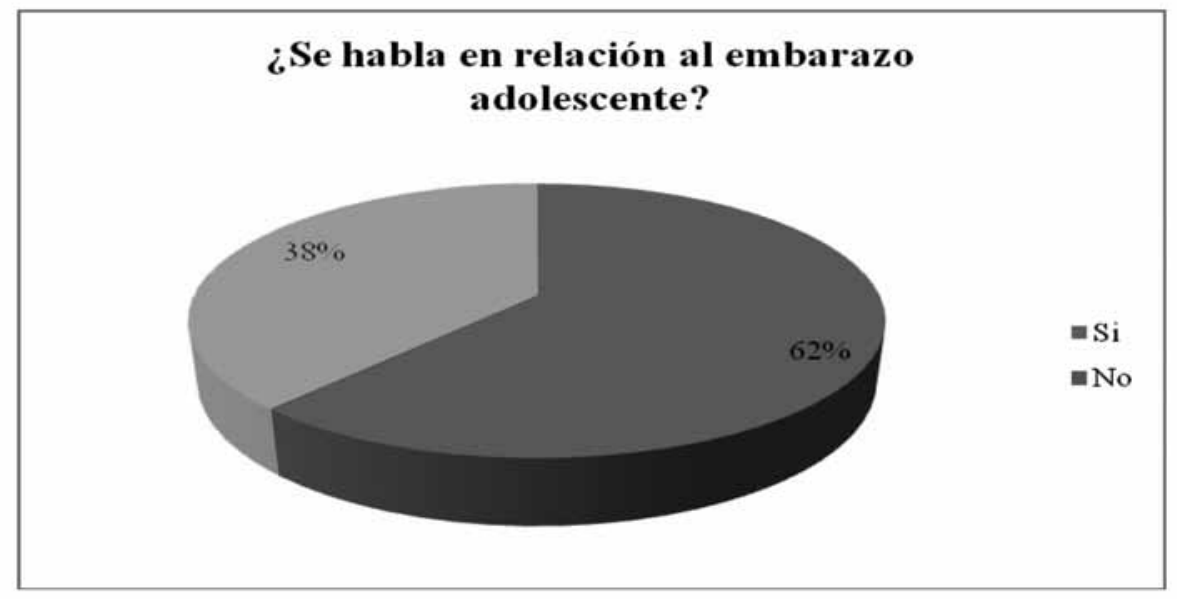

En cuanto a la pregunta sobre si se habla de embarazo adolescente en la escuela, el $62 \%$ de los alumnos entrevistados responde afirmativamente. De ese porcentaje, un $62 \%$ expresa que se habla sin detalle, y un $23 \%$ refiere que hay adolescentes embarazadas en la escuela, que aparecen como el motivo por el que se habla.

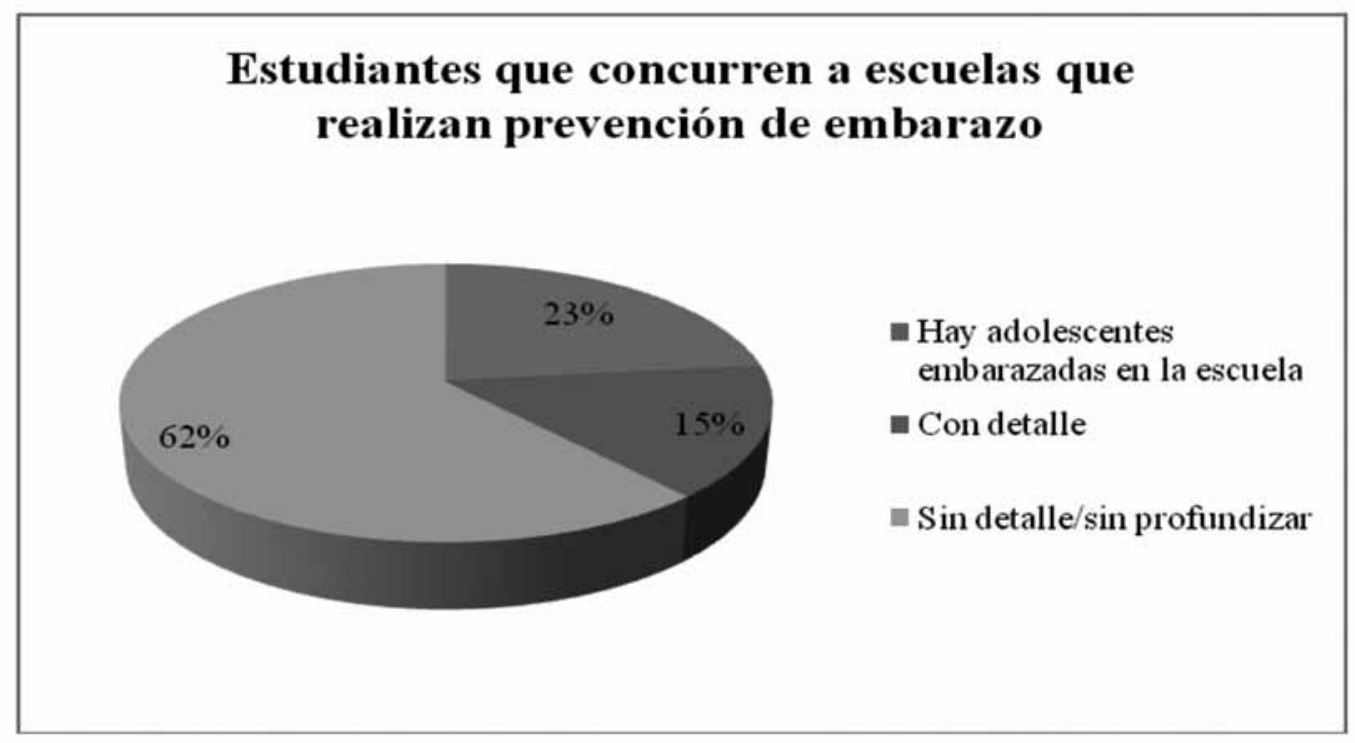

En este sentido, se puede ver que el abordaje del embarazo adolescente es escaso, dado que solo un $15 \%$ manifiesta que se habla con detalle de dicha situación. Por otro lado, cabe interrogarse sobre la necesidad de la implementación de la educación sexual integral no solo para prevenir embarazos, sino también enfermedades de transmisión sexual, así como diversos aspectos sobre la sexualidad humana. 
1.4 En tu escuela, ¿se hace prevención sobre la toma de alcohol y drogas?

En cuanto a la prevención sobre alcohol y drogas, el 58 \% de las personas entrevistadas manifiestan que sí se realiza en la escuela, aunque un 82 \% expresa que se aborda el tema, pero sin profundizar. Excepcionalmente se elaboran trabajos prácticos, muchas veces dirigidas por un docente comprometido con esta problemática.

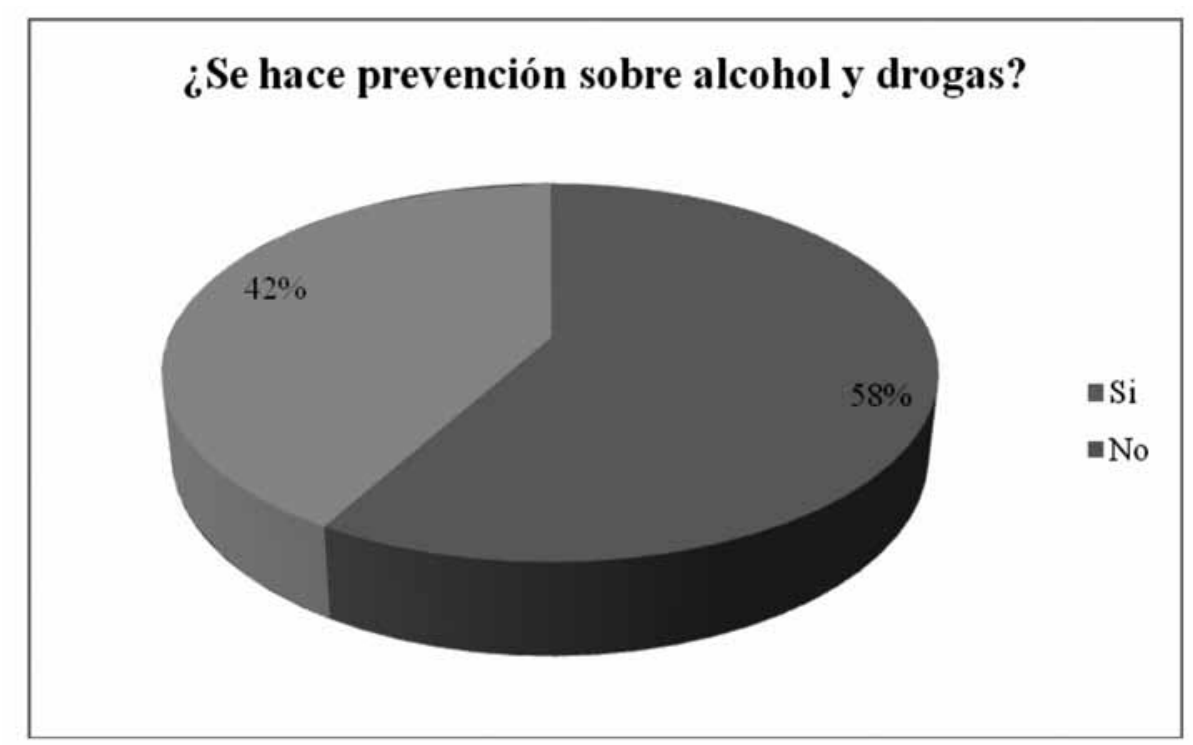

1.5¿Se estimulan trabajos prácticos individuales o grupales sobre estos temas?

En cuanto a la realización de tareas o trabajos, ya sean individuales o grupales, el 93 \% no realiza trabajos sobre estos temas. El $7 \%$ restante los desarrolla en alguna materia en particular, pero no como práctica frecuente.

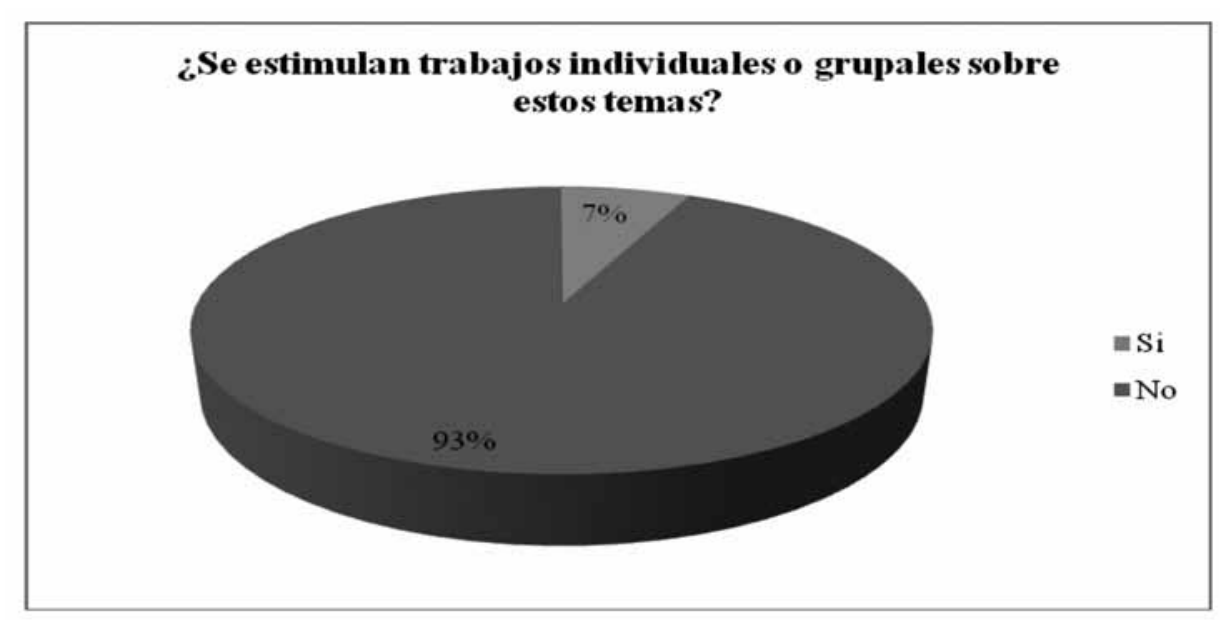


1.6 ¿Se comenta la influencia sobre la propaganda y los medios de comunicación?

Respecto a la influencia de los medios de comunicación, en lo que se refiere a la propaganda sobre bebidas alcohólicas y cigarrillos, el $68 \%$ refiere que no se aborda la problemática de las adicciones desde esta perspectiva.

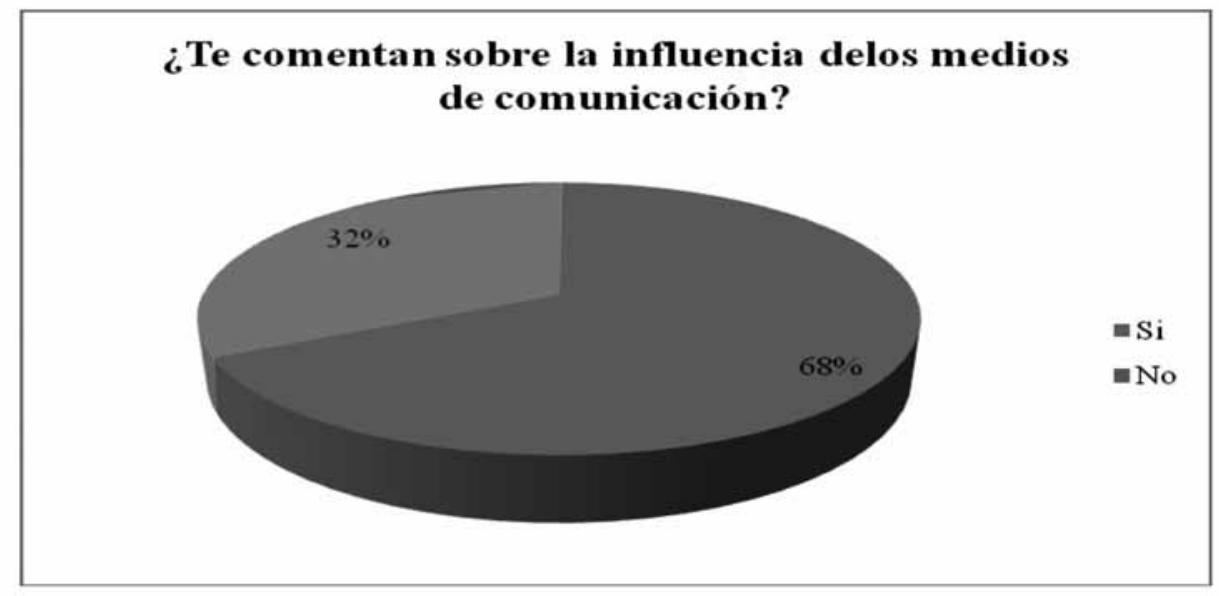

1.7 ¿Se comenta y considera la importancia del trabajo y los estudios para el futuro?

Respecto a si reciben explicaciones y comentarios acerca de la importancia del trabajo y el futuro, el 90 \% manifiesta que sí.

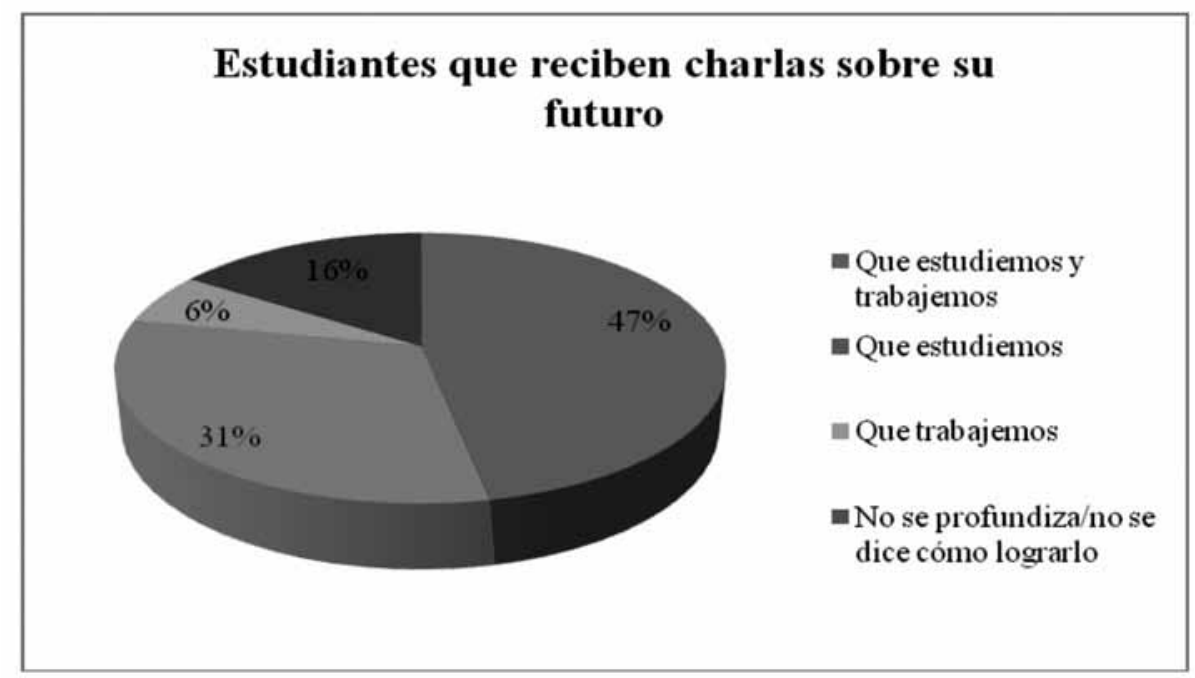

Dentro de las conversaciones, el $47 \%$ refiere que le hablan sobre la importancia de estudiar y trabajar, el $31 \%$ se siente impulsado a seguir estudiando, y el 6\% a buscar trabajo. Los argumentos que reciben proponen seguir estos caminos con el objeto de tener trabajos decentes y poder sostenerse económicamente. Un $16 \%$ de los que reciben charlas, expresan que no se profundiza al respecto y no saben cómo lograrlo. Es decir, no saben cómohacer para seguir estudiando o para poder conseguir un trabajo. 
2. Desde el punto de vista de la salud pública

Análisis de frecuencias multivariadas de la atención recibida por los adolescentes en los centros de salud y unidades funcionales

\subsection{Accesibilidad}

Los tiempos de los adolescentes son de características particulares. Las necesidades de hoy tienen una inmediatez que si no son atendidas, probablemente no vuelvan a consultar. De ahí la importancia de su atención para no generar oportunidades y perderlas. Si bien el tiempo de menos de 3 días (48,3 \%) entre la solicitud del turno y su asignación sería una buena accesibilidad, para los adolescentes podría ser tarde.

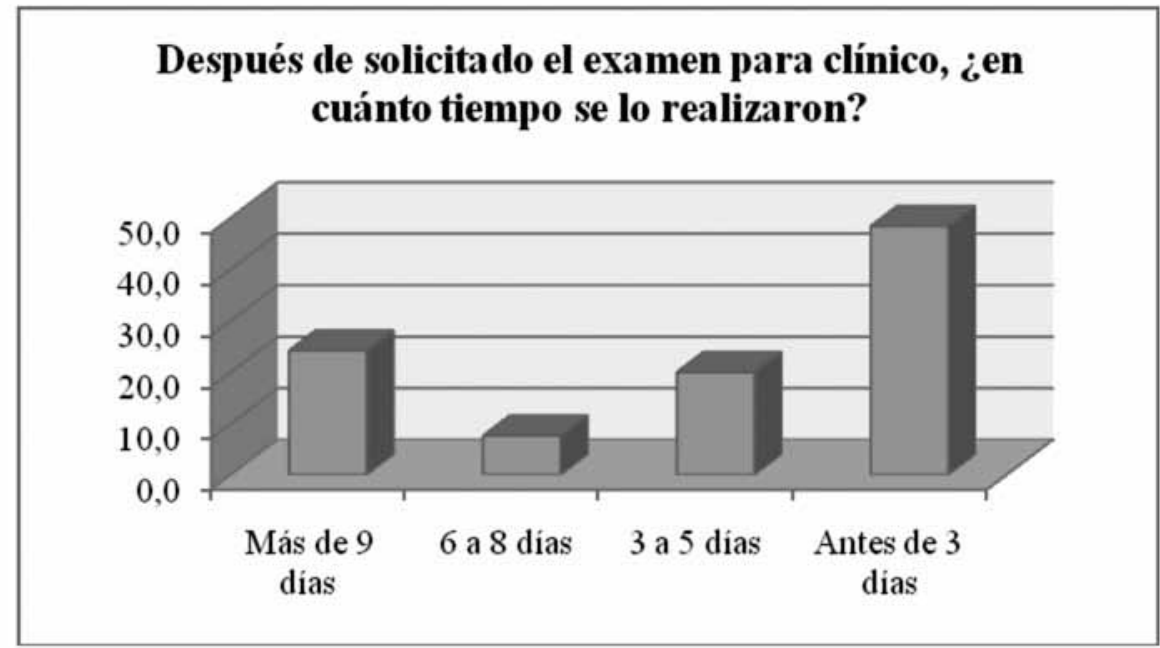

\begin{tabular}{|l|c|}
\hline $\begin{array}{l}\text { Después de solicitado el examen para clínico, } \\
\text { ¿en cuánto tiempo se lo realizaron? }\end{array}$ & Porcentaje \\
\hline Más de 9 días & 24,2 \\
6 a 8 días & 7,6 \\
3 a 5 días & 19,9 \\
Antes de 3 días & 48,3 \\
Total & 100,0 \\
\hline
\end{tabular}

\section{Los medicamentos formulados, ¿fueron entregados en su totalidad?}

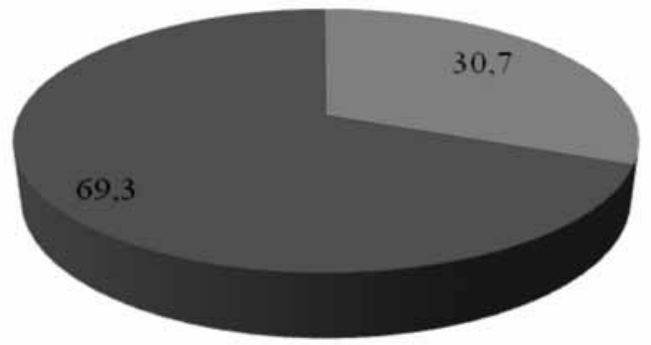




\subsection{Oportunidad}

Las oportunidadesson otro factor importante en la adolescencia. En la entrevista hay siempre dos motivos de consulta, que son las siguientes:

- El motivo real o aparente es lo que el paciente trae implícitamente. (Ej.: cefalea, problemas ginecológicos, etc.)

- El motivo no real es lo que debe surgir en una buena entrevista, para lo que se necesita tiempo de escucha, confianza, respeto y sin imposición de nuestros valores. (Por ejemplo, el uso y abuso de drogas, o los trastornos de conducta alimentaria). Necesitamos para ello rapidez en la atención, en lo posible el mismo día que concurre el adolescente y extremar la puntualidad (puntualmente, $32,3 \%$ en nuestro estudio. Como ocurre con la accesibilidad; menos de 2 días (65,9\%) entre la asignación de la cita y la atención podría implicar una oportunidad perdida.

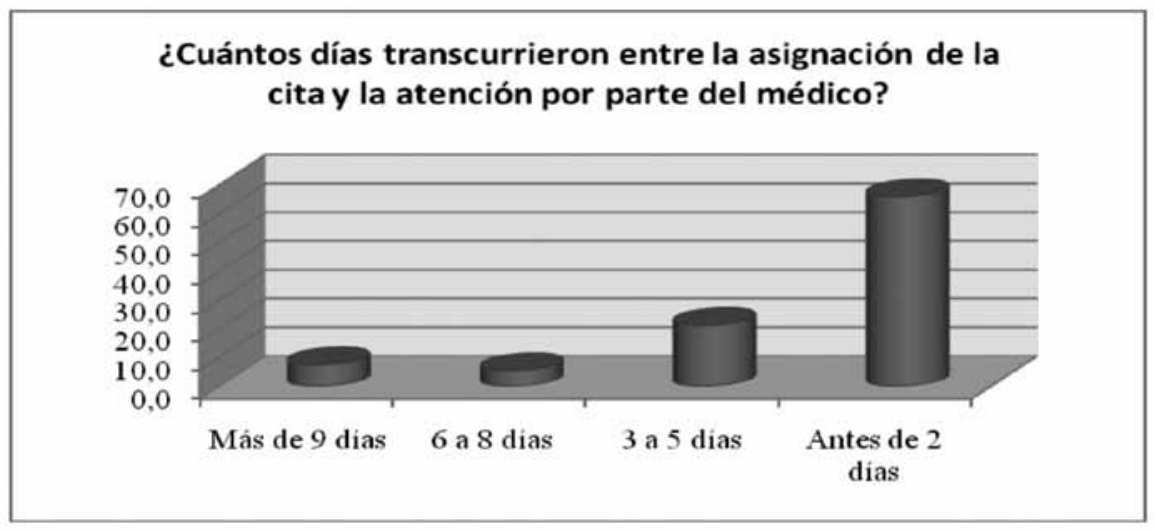

\begin{tabular}{|l|c|}
\hline $\begin{array}{l}\text { ¿Cuántos días transcurrieron entre la asignación } \\
\text { de la cita y la atención por parte del médico? }\end{array}$ & Porcentaje \\
\hline Más de 9 días & 7,4 \\
6 a 8 días & 5,4 \\
3 a 5 días & 21,2 \\
Antes de 2 días & 65,9 \\
Total & 100,0 \\
\hline
\end{tabular}

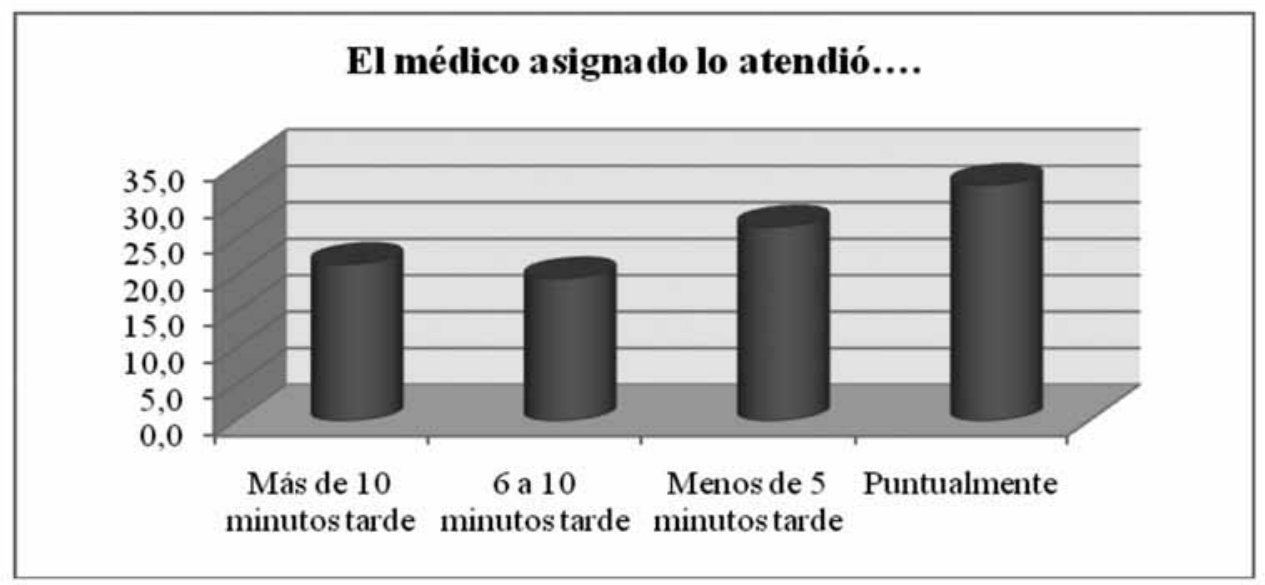




\begin{tabular}{|l|c|}
\hline El médico asignado lo atendió.... & Porcentaje \\
\hline Más de 10 minutos tarde & 21,5 \\
6 a 10 minutos tarde & 19,5 \\
Menos de 5 minutos tarde & 26,6 \\
Puntualmente & 32,3 \\
Total & 100,0 \\
\hline
\end{tabular}

\subsection{Oportunidad}

\section{¿Cuánto tiempo tuvo que esperar para que le} dispensaran los medicamentos en la farmacia?

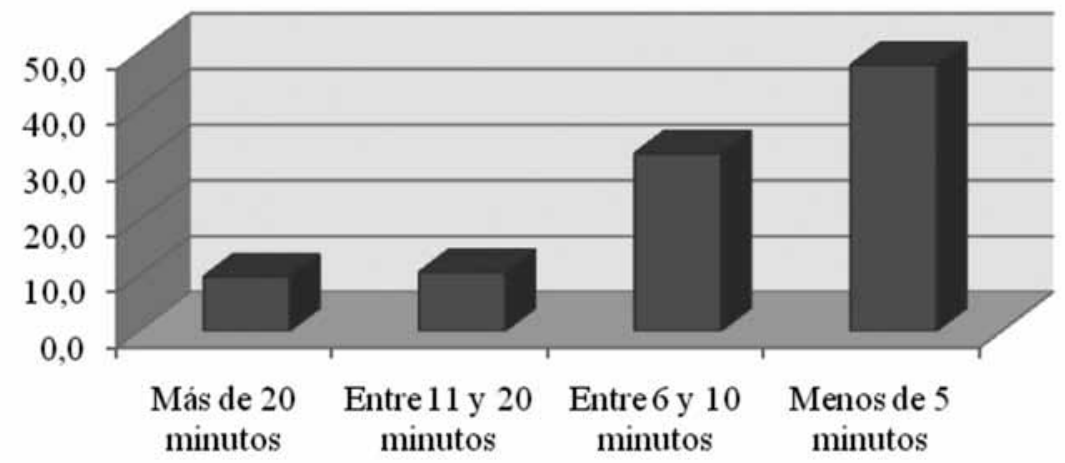

\begin{tabular}{|l|c|}
\hline $\begin{array}{l}\text { ¿Cuánto tiempo tuvo que esperar para que le } \\
\text { dispensaran los medicamentos en la farmacia? }\end{array}$ & Porcentaje \\
\hline Más de 20 minutos & 9,8 \\
Entre 11 y 20 minutos & 10,6 \\
Entre 6 y 10 minutos & 31,9 \\
Menos de 5 minutos & 47,8 \\
Total & 100,0 \\
\hline
\end{tabular}




\subsection{Trato digno}

\section{La actitud y trato que usted recibió de su médico tratante fue....}

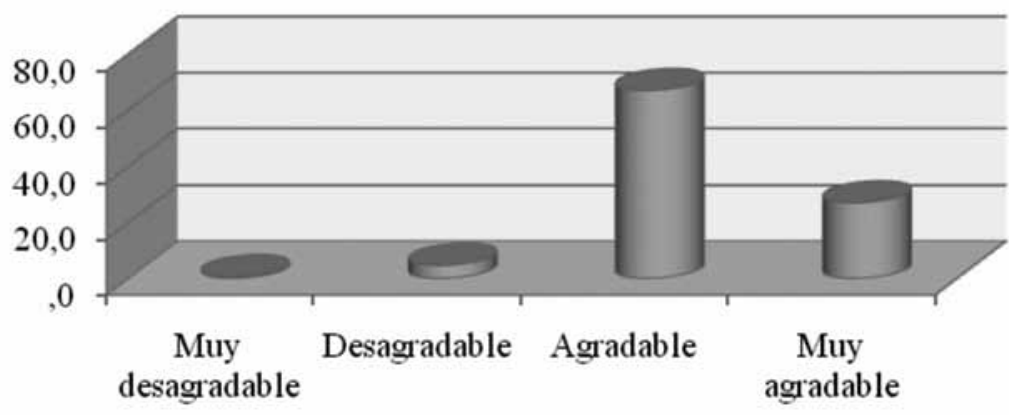

\begin{tabular}{|l|c|}
\hline La actitud y el trato que usted recibió de su & Porcentaje \\
\hline médico tratante fueron... & 0,8 \\
Muy desagradables & 4,1 \\
Agradables & 73,9 \\
Muy agradables & 21,2 \\
Total & 100,0 \\
\hline
\end{tabular}

El trato digno implica tiempo, confianza, respeto, trato amistoso, no amiguismo, sin imponer nuestros valores éticos, religiosos ni morales. Para conseguir un trato digno con nuestros pacientes, tanto médicos como enfermeras y administrativos de farmacia, debemos lograr ofrecer trato muy agradable o agradable (21,2 y 73,9 \% respectivamente), que por las estadísticas se ha logrado satisfactoriamente

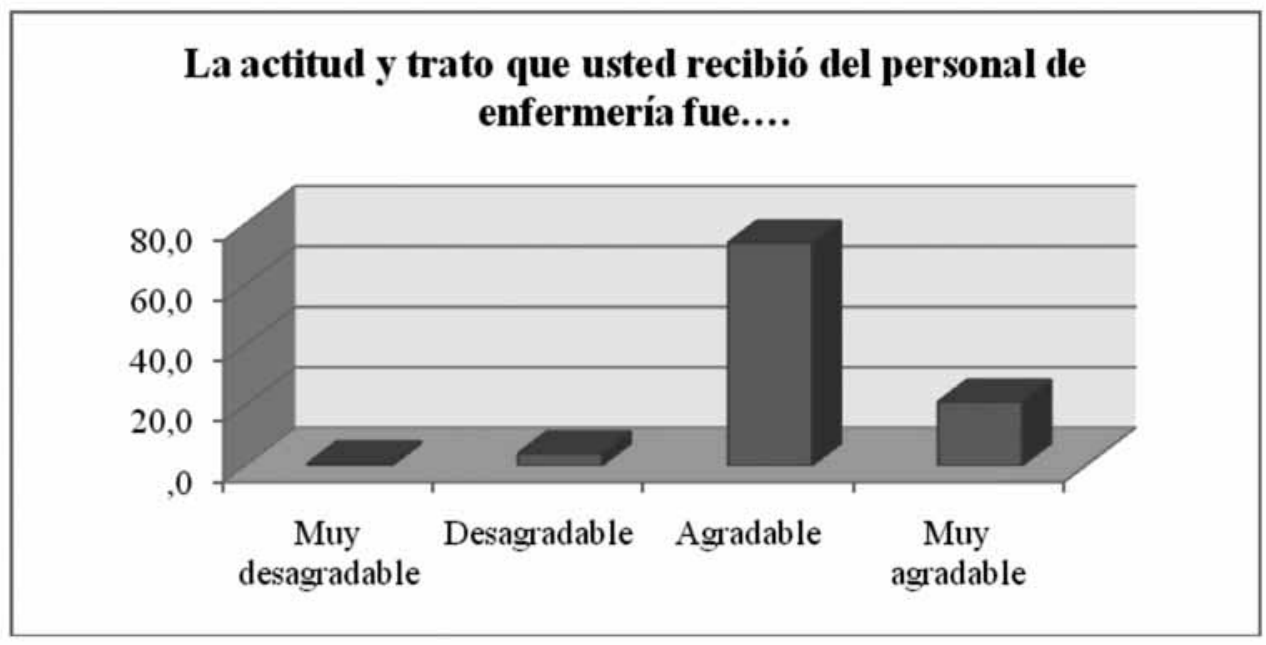




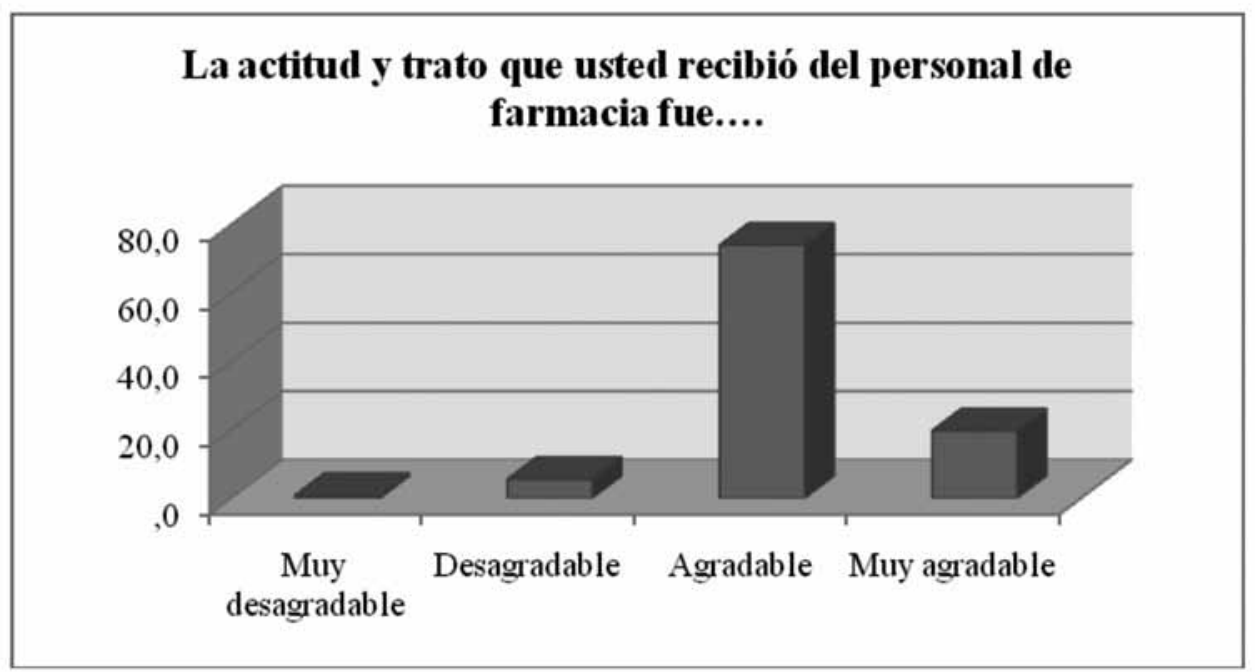

\subsection{Información}

La información por parte del médico, de enfermeras y del personal de farmacia resultó clara y muy clara, lo cual garantiza el éxito en un tratamiento, la consejería sobre sexualidad responsable, la prevención de embarazo no esperado y en evitar enfermedades de transmisión sexual.

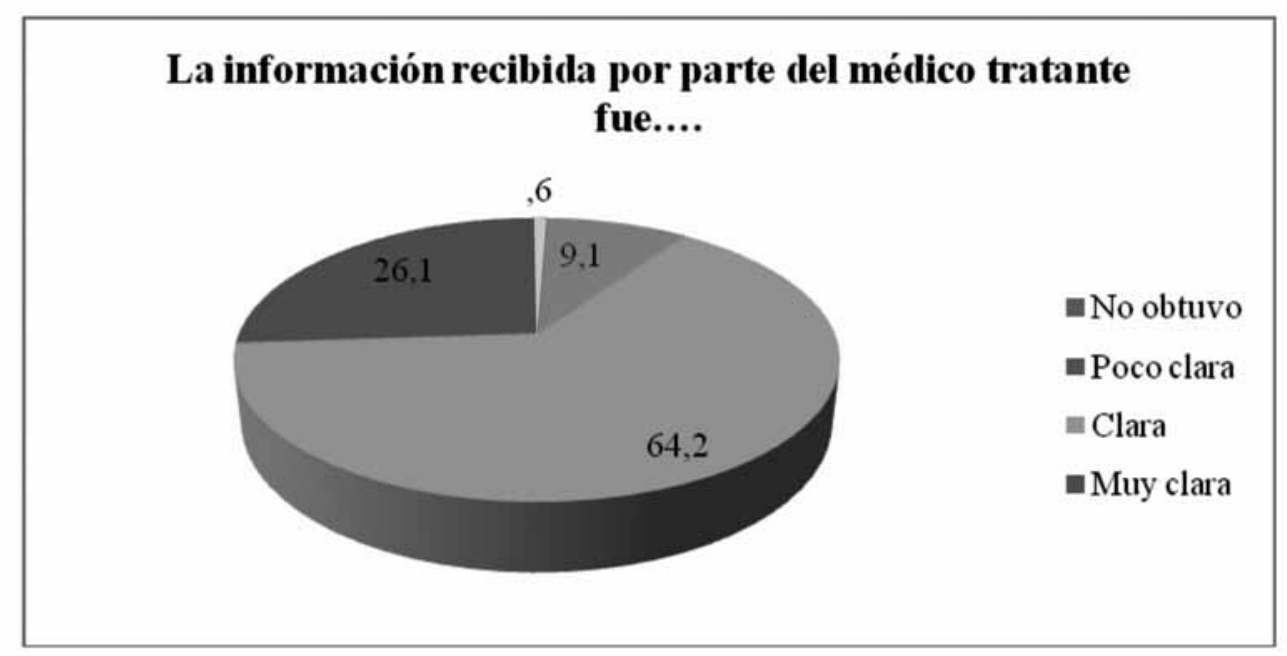




\section{La información recibida por parte del personal de enfermería fue....}

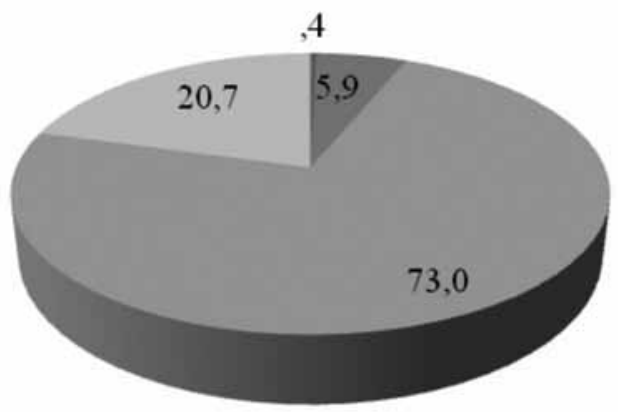

No obtuvo

- Poco clara

Clara

- Muy clara

\section{La información recibida por parte del personal de} farmacia fue....

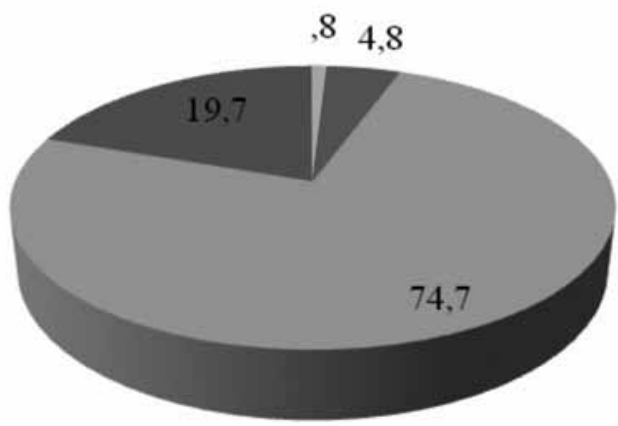

No obtuvo

- Poco clara

- Clara

- Muy clara 


\subsection{Calidad de servicio}

Tanto la calidad como la estructura de servicio estadísticamente son bien calificadas por los usuarios. El municipio de Malvinas Argentinas, del cual depende la salud pública, sostiene el gasto mediante la coparticipación provincial (Buenos Aires), nacional, los recursos municipales y aportes de las obras sociales de los pacientes que utilizan nuestros servicios y por el pago de particulares que no tienen domicilio en nuestra localidad.

\section{¿Cómo califica usted la calidad de los servicios médicos recibidos durante su atención, con respecto al diagnóstico de su enfermedad?}

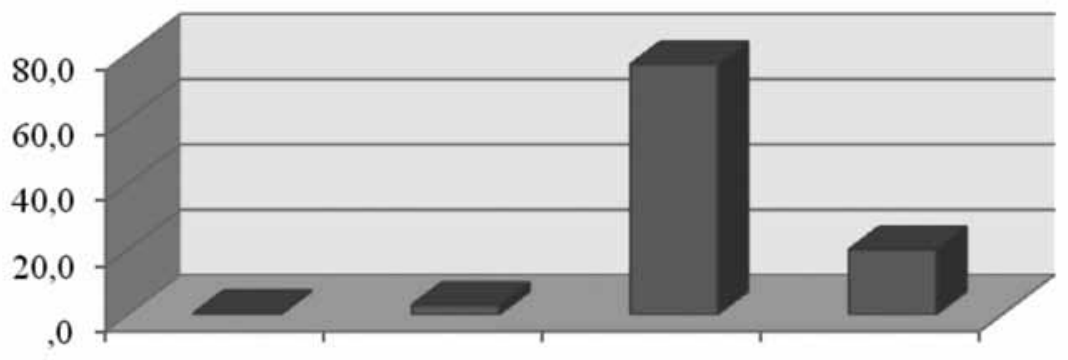

Pésima Mala Buena Excelente

\begin{tabular}{|l|c|}
\hline \multicolumn{2}{|l|}{ ¿Cómo califica usted la calidad de los servicios } \\
médicos recibidos durante su atención, con \\
respecto al manejo de su enfermedad? & Porcentaje \\
\hline Pésima & 0,4 \\
Mala & 2,9 \\
Buena & 76,7 \\
Excelente & 20,0 \\
Total & 100 \\
\hline
\end{tabular}

\section{¿Cómo califica usted la calidad de los servicios médicos recibidos durante su atención, con respecto al manejo de su enfermedad?}

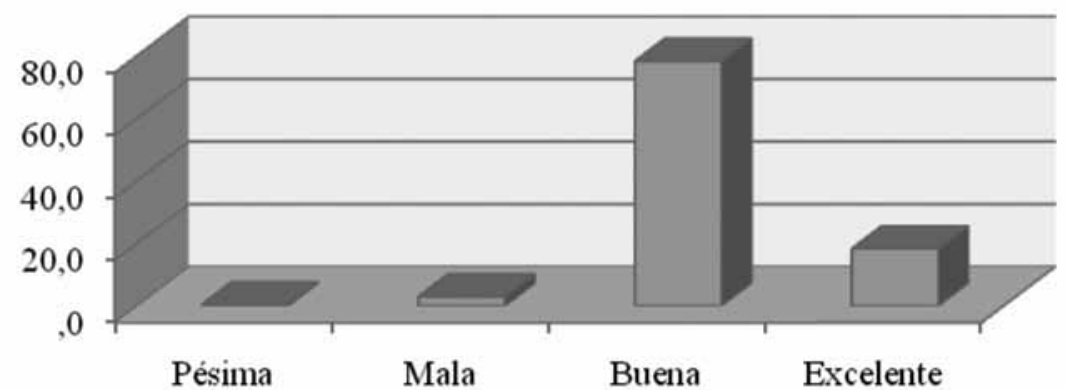




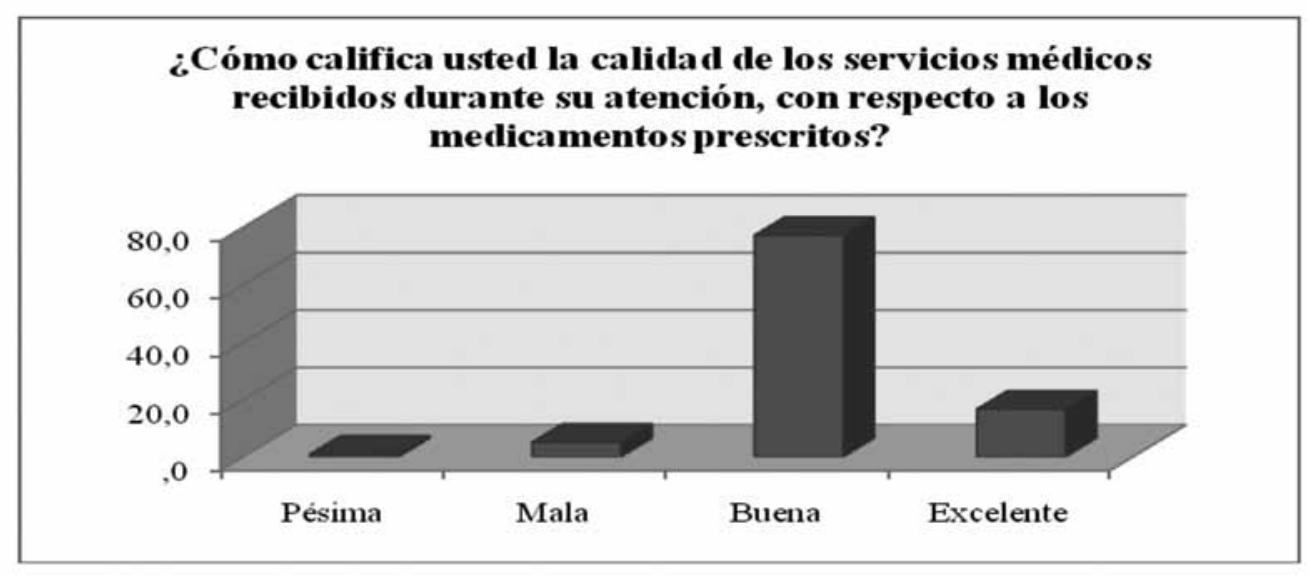

\begin{tabular}{|c|c|}
\hline $\begin{array}{l}\text { ¿Cómo califica usted la calidad de los servicios } \\
\text { médicos recibidos durante su atención, con } \\
\text { respecto a los medicamentos prescritos? }\end{array}$ & Porcentaje \\
\hline Pésima & 0,4 \\
\hline Mala & 3 \\
\hline Buena & 78,3 \\
\hline Excelente & 18,3 \\
\hline Total & 100,0 \\
\hline
\end{tabular}

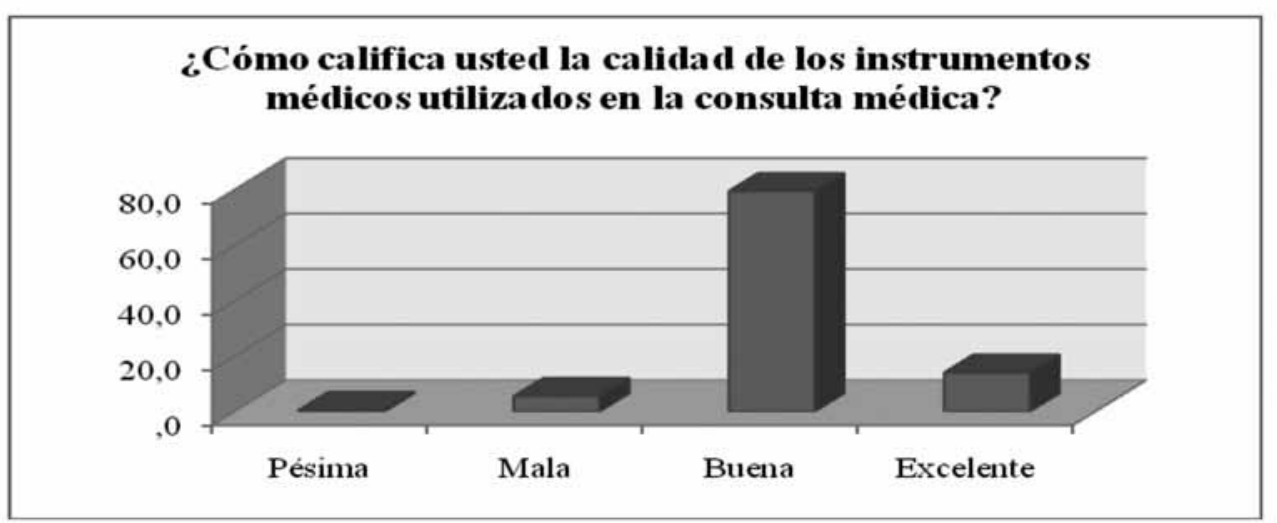




\subsection{Estructura del servicio}

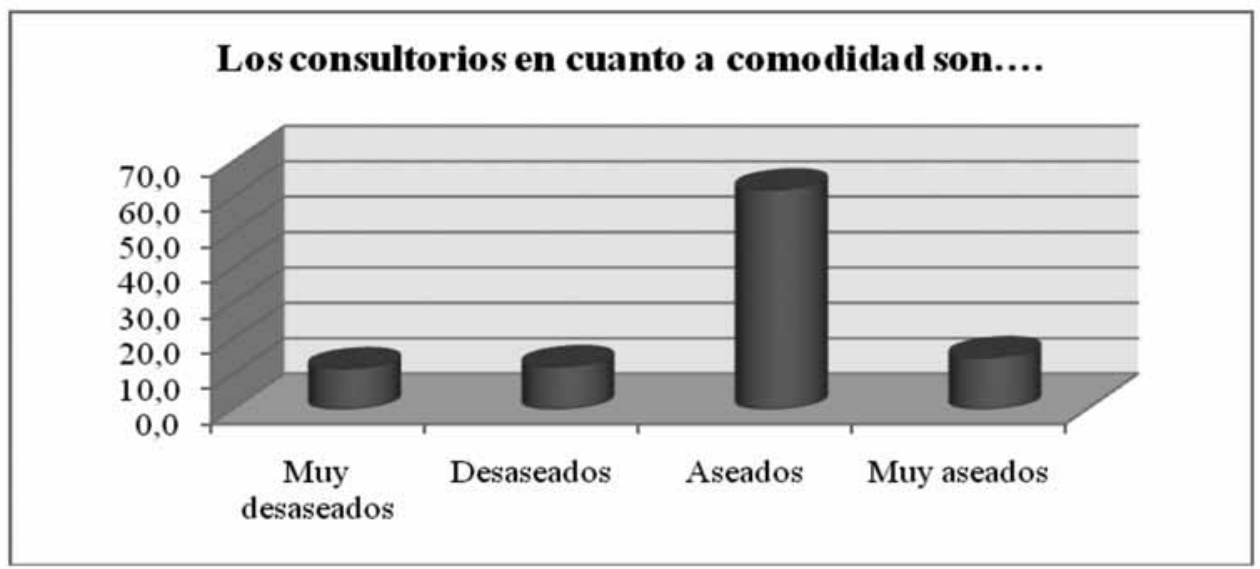

\begin{tabular}{|c|c|}
\hline $\begin{array}{l}\text { ¿Cómo califica usted la calidad de los servicios } \\
\text { médicos recibidos durante su atención, con } \\
\text { respecto a los medicamentos prescritos? }\end{array}$ & Porcentaje \\
\hline Muy desaseados & 11,5 \\
\hline Desaseados & 12 \\
\hline Aseados & 61,9 \\
\hline Muy aseados & 14,6 \\
\hline Total & 100,0 \\
\hline
\end{tabular}

\section{La sala de espera y baños en cuanto a comodidad} son....

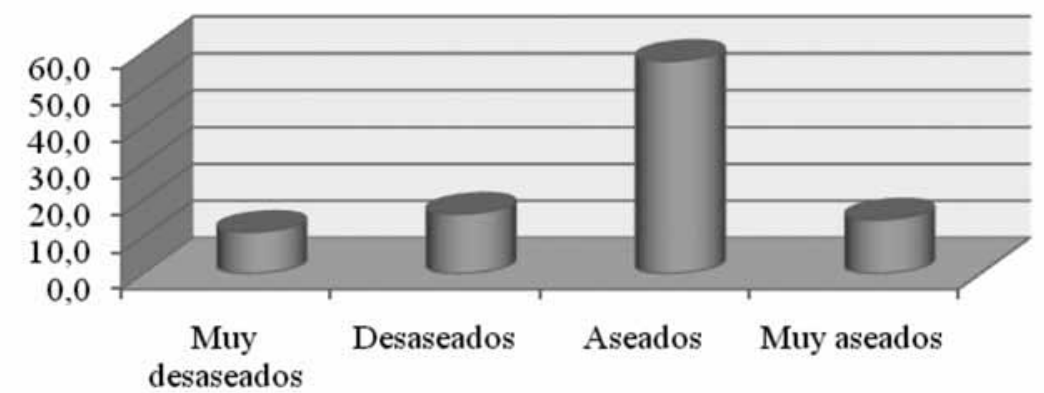




\section{Los consultorios en cuanto a limpieza son....}

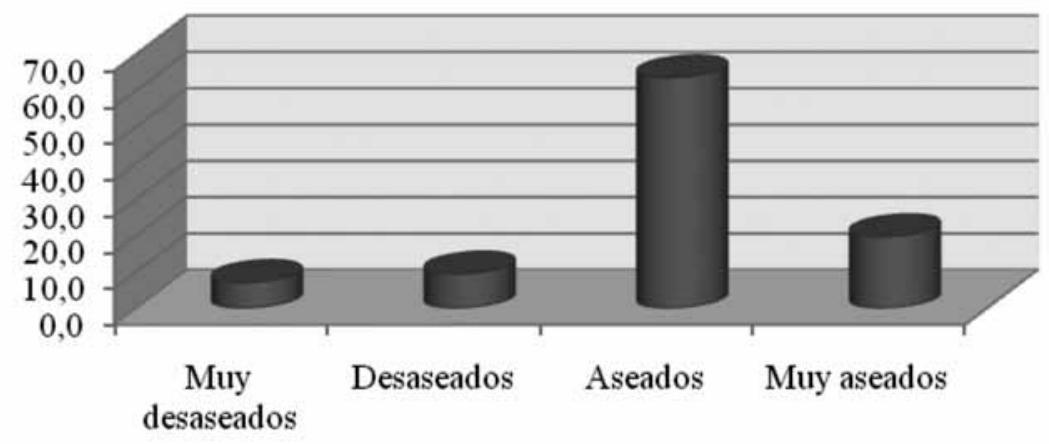

\begin{tabular}{|l|c|}
\hline Los consultorios, en cuanto a limpieza, son... & Porcentaje \\
\hline Muy desaseados & 11,5 \\
Desaseados & 12 \\
Aseados & 61,9 \\
Muy aseados & 14,6 \\
Total & 100,0 \\
\hline
\end{tabular}

\section{La sala de espera y baños en cuanto a limpieza es....}

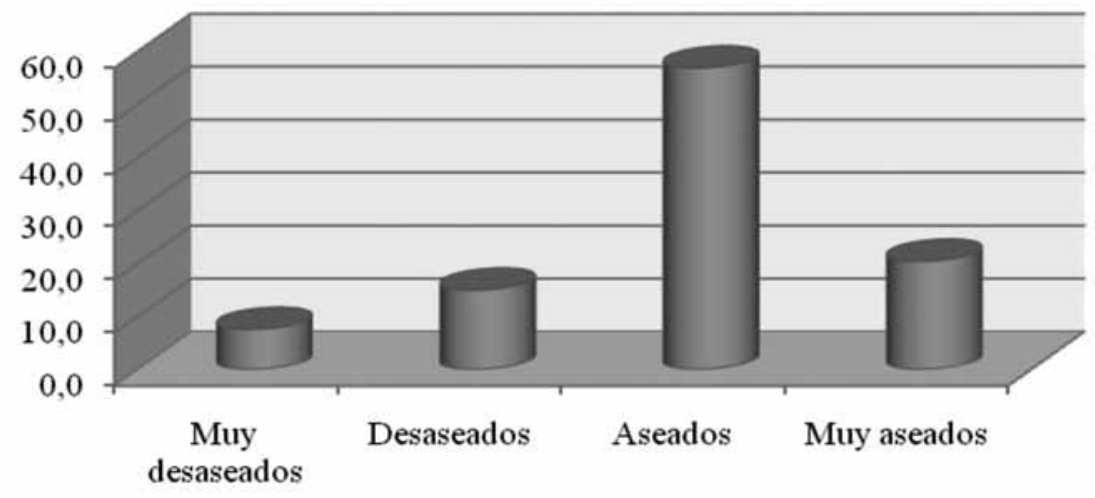

\begin{tabular}{|l|c|}
\hline La sala de espera y baños en cuanto a limpieza es... & Porcentaje \\
\hline Muy desaseados & 11,4 \\
Desaseados & 16,2 \\
Aseados & 57,7 \\
Muy aseados & 14,7 \\
Total & 100,0 \\
\hline
\end{tabular}




\section{Análisis/Discusión}

\section{Desde la educación}

Para alcanzar los importantes objetivos propuestos para el trabajo de investigación, se debió comenzar por conocer qué ocurre en la escuela, analizando, mediante entrevistas a alumnos de $1 \mathrm{er}, 2{ }^{\circ}$ y $3 e r$ año, considerando las dimensiones: el tratamiento de los problemas en la escuela; ¿se habla y previene la violencia?, ¿se habla en relación con el embarazo adolescente?, ¿se hace prevención sobre la toma de alcohol y drogas?, ¿se estimulan trabajos prácticos individuales o grupales sobre estos temas?, ¿se comenta la influencia sobre la propaganda y los medios de comunicación?, y ¿se comenta y considera la importancia del trabajo y los estudios para el futuro?

En cuanto a la dimensión Tratamiento de los problemas en tu escuela, los alumnos respondieron, en cierta forma con dudas, o mencionando casos puntuales, lo que sugiere que la metodología para atender sus problemas no está consolidada, constituyendo una debilidad en el ámbito educativo.

En el caso del tratamiento de la violencia, si bien un $84 \%$ de los estudiantes entrevistados expresaron que se han considerado estos temas, solo el $8 \%$ refirió que ha sido producto del diseño curricular, o bien, tratado sistemáticamente en clase, lo que representa también una debilidad en cuanto al proceso de enseñanza-aprendizaje.

En la dimensión Embarazo adolescente, se comprueba que un $15 \%$ de los alumnos han recibido conocimientos relacionados con esta problemática. El tema Adicciones, al ser consultado con los estudiantes, el $82 \%$ manifestó que el abordaje ha sido de escasa profundidad. Al respecto, el 23\% refirió que hay adolescentes embarazadas en la escuela.

Los cuatro puntos precedentes, en cierta forma, tienen relación por su gravedad en la formación adolescente, y más aun teniendo en cuenta el contexto al cual se ha enfocado este trabajo de investigación, que en especial considera zonas carenciadas, población vulnerable, pobreza y escaso nivel educativo. Esta circunstancia, que se replica en otros asentamientos y villas de emergencia, requiere, exige, compromiso y un esfuerzo paradigmático de la escuela, sus directivos y profesores, que podrían sintetizarse de la siguiente forma:
1.1 Elaborar un diseño curricular escrito y actualizado, analizado y aprobado por las autoridades educativas, que aseguren el dictado sistemático de asignaturas sobre educación sexual y reproductiva y otra sobre prevención de las adicciones, que abarque los 5 años del nivel secundario.

1.2 Lograr la participación activa de directivos y de todos los docentes, alumnos, e involucrando a padres y tutores hoy no integrados a la escuela.

1.3 Instrumentar un sistema de evaluación, estableciendo claramente las responsabilidades de directivos y docentes sobre la actividad desarrollada, los apuntes entregados, libros sugeridos, videos, las películas y los resultados alcanzados en los alumnos.

En relación con la dimensión Elaboración de trabajos prácticos, individuales o grupales, se destaca las previsiones ya existentes en la materia Construcción de Ciudadanía. Al respecto, los temas que deben proponer los alumnos también deberían considerar los temas precedentes, la "influencia de los medios masivos de comunicación", siendo necesario elaborarse estos trabajos, proyectos, y quedar registrados para su evaluación real.

Sobre las motivaciones para pensar "el futuro" de los estudiantes, se desprende que es clara la preocupación de los equipos directivos y ciertos docentes al promover su tratamiento y discusión, donde solo el $16 \%$ de los alumnos entrevistados apreció que la profundidad del dictado es reducida, constituyendo así una fortaleza de las escuelas en cuanto a esta importante problemática considerada.

\section{Desde la salud pública}

Los valores en el registro de venta de drogas son más altos en las regiones urbanas de mayor concentración de población del Amba o Gran Buenos Aires, zonas similares al sector donde se aplicaron las encuestas y entrevistas. Las situaciones de violencia y la percepción de inseguridad son condiciones altamente probables de presentarse entre los hogares que registran estar bajo problemas por altos consumos de alcohol. En los últimos 7 años se registra un incremento del consumo de alcohol en la franja etaria más joven (12 a 17 años), consistente con la baja en la edad de inicio de consumo, llegando a alcanzar el $50 \%$ de acuerdo 
a la Sexta Encuesta Nacional a Estudiantes de Enseñanza MediaArgentina. ${ }^{26}$

En las encuestas ya validadas para la recolección de datos, aplicadas a los adolescentes de 12 a 18 años, en las siete unidades funcionales referidas, se consideraron las siguientes dimensiones: Accesibilidad, Oportunidad, Trato digno, Información, Calidad de servicio y Estructura del servicio.

Al respecto, y en cuanto a la atención médica recibida, se observan importantes resultados. En la dimensión Accesibilidad, es de destacar que un $48 \%$ de los encuestados recibió su turno dentro de los 3 días, lo cual es un muy buen indicador y demuestra la importancia de estructurar un sistema amplio de atención primaria de la salud mediante centros de salud y unidades funcionales adecuadamente distribuidos en todo el partido de Malvinas Argentinas.

Sí, teniendo en cuenta la personalidad en formación del adolescente, quizás debería lograrse su acceso al servicio médico con mayor rapidez. Paralelamente se destaca el acceso a los medicamentos, que ha sido posible en un 69,3\%, lo cual, en relación con las carencias que se comprueban de todo orden en general en la salud pública, es una respuesta muy adecuada a dichas necesidades.

En lo relativo a "oportunidad", se destaca que un $65,9 \%$ de los alumnos encuestados fueron atendidos por un médico dentro de los 2 días, representando otro buen indicador general, sin dejar de tener en cuenta que, en el caso de los adolescentes, puede llegar a ser una oportunidad perdida. Sí es de destacar que el 59 \% fue recibido por el médico en un tiempo menor a los 5 minutos, al igual que la entrega de medicamentos, que se hizo en escasos minutos. Otra dimensión de alta importancia es Trato digno, donde un 95,1 \% manifiesta haber recibido un trato entre "muy agradable" y "agradable", que evidentemente conforma una señal de respeto, consideración y retención de pacientes significativo. Prácticamente, el trato de enfermería y del personal de farmacia tiene similares indicadores a los ya referidos precedentemente.
La dimensión Información, de acuerdo con los datos obtenidos yla información brindada por parte del médico, enfermería y farmacia, supera el 90 \% de aprobación, resaltando, en primer lugar, la información suministrada por farmacia.

En cuanto a la dimensión Calidad de servicio, los adolescentes encuestados manifestaron que el diagnóstico de la enfermedad, los medicamentos prescriptos y los instrumentos médicos utilizados para su tratamiento en las siete unidades funcionales fueron un $20 \%$ excelentes y más de un $70 \%$ buenos, lo que resulta y constituye una excelente señal para los futuros pacientes de este grupo etario.

Finalmente, en relación con la dimensión Estructura del servicio recibido, tanto la comodidad de los consultorios, las salas de espera y los baños como la limpieza general de las instalaciones son muy adecuados.

\section{Propuestas}

\section{Desde la educación. Introducción}

El concepto más representativo sobre lo que significa la escuela, lo expone el profesor Marcelo Krichesky de la siguiente forma:

Una escuela abierta a la comunidad implica una redefinición del concepto de comunidad educativa, que no lo restringe al escenario de la escuela, sus docentes, alumnos y padres, sino que se abre al espacio público local, incluyendo como agentes de enseñanza y aprendizaje a las familias, iglesias, clubes, organizaciones de vecinos, bibliotecas, organizaciones productivas, con el objetivo de construir un proyecto educativo y cultural que parta de las necesidades y posibilidades de la comunidad. ${ }^{27}$

Se trata de crear espacios de participación y reflexión, promover discusiones grupales, dejar entrar la vida de los chicos y chicas a la escuela, que puedan expresar lo que piensan, lo que sienten, lo que quieren, que puedan encontrar en los docentes, a adultos disponibles capaces

26 Sexta Encuesta Nacional a Estudiantes de Enseñanza Media Argentina. Recuperado el 16 de febrero de 2018de http://www.observatorio.gov.ar/media/k2/ attachments/VIZEstudioZ NacionalZaZEstudiantesZdeZNivelZMedioZ-ZReginZCuyoZ-ZAoZ2014_1.pdf

27 Krichesky, M. (2006). Escuela y comunidad: desafíos para la inclusión educativa- 1.a ed. Buenos Aires: Ministerio de Educación, Ciencia y Tecnología de la Nación. 
de escuchar sus preguntas, sus dudas, sus incertidumbres (CFE). ${ }^{28}$

\subsection{Los problemas planteados por los adolescentes.} Cada escuela debería registrar y realizar su seguimiento, incluyendo el llamado a los padres o tutores para informarles las eventuales situaciones que se presenten y coordinar posibles derivaciones o plantear soluciones.

1.2 La problemática de la violencia. Tendrá que ser tratada no solo por lo que pueda ocurrir en el interior del establecimiento educativo, sino para prevenir la participación de los adolescentes en hechos de violencia en la familia y en la vía pública.

1.3 El embarazo adolescente. Se considera necesario abordar este y otros temas relacionados durante los 5 años del nivel secundario. Con respecto a las asignaturas y espacios curriculares, se destaca la Nueva escuela secundaria, Ciudad de Buenos Aires. ${ }^{29}$ En ella, se propone y determina a las escuelas que es imprescindible realizar un diseño curricular ajustado a las necesidades educativas de la comunidad. Cada escuela debe hacerlo. Y las autoridades educativas tienen que evaluarlo. Analiza su marco normativo, marco pedagógico, enseñanza para una escuela de calidad para todos los estudiantes (pp. 53-60).

En cuanto a la asignatura Educación Sexual Integral (pp. 569600) se establece la obligatoriedad de dictado sistemático durante los 5 años del nivel secundario. Se proporcionan los objetivos y los contenidos sugeridos de acuerdo con la Ley n. ${ }^{\circ} 2110 / 06$, espacios curriculares específicos y obligatorios, dimensiones y ejes de contenidos.

Durante el año 2017, el Programa Nacional de Educación Sexual Integral incluye el "Plan Nacional de Prevención del Embarazo No Intencional en la Adolescencia", que resulta de la acción intersectorial coordinada por la Secretaría Nacional de Niñez, Adolescencia y Familia, en la que participan los ministerios de Educación, Salud, Desarrollo Social y la Fundación Centro de Implementación de Políticas Públicas para la Equidad y el Crecimiento. Paralelamente, la Resolución 322/17 del Consejo Federal de Educación aprueba la campaña nacional sobre embarazo no intencional en la adolescencia a cargo del Programa Nacional de Educación Sexual Integral. El citado plan propone materiales pedagógicos y didácticos necesarios para comenzar la formación de los adolescentes en temas de salud sexual integral, donde la escuela puede cumplir un papel esencial.

1.4 La problemática de adicciones. Debe constituirse en una asignatura a nivel de escuela secundaria, ante la epidemia actual en materia del consumo de alcohol y drogas.

Así es considerada en el diseño curricular de la Nueva Escuela Secundaria de la Ciudad de Buenos Aires. Al respecto, se propone la materia Educación y Prevención sobre Adicciones (pp. 602-620). Se detallan los objetivos, contenidos troncales, los espacios curriculares específicos y obligatorios (Eceo); se utilizarán formatos pedagógicos participativos (talleres u otras modalidades pedagógicas no tradicionales según Res. 93/ 2009, Consejo Federal de Educación). El desarrollo del Eceo en dos de los tres trimestres, de modo tal que garantice la continuidad y sistematismo en el tratamiento a lo largo del año. La carga horaria es de 480 minutos por año, durante el primer año y en el segundo año de nivel secundario. Se incluye la metodología de evaluación a los alumnos de estos contenidos, para lo cual se tendrá en cuenta la participación activa de alumnos y docentes, cada uno desde sus lugares y responsabilidades.

1.5 Realización de trabajos prácticos. Estas actividades curriculares, perfectamente referidas ya en la asignatura Construcción de Ciudadanía, (Dirección General de Cultura y Educación, 2007, p. 37), contienen todos los elementos indispensables para su desarrollo adecuado, donde la responsabilidad profesional de directivos y docentes hará posible involucrar a los estudiantes, sus familias y otras organizaciones educativas y sociales.

1.6 La influencia sobre la propaganda y los medios de comunicación. Se enseñará a analizar e interpretar con profundidad los mensajes que promueven el consumo excesivo de alcohol y otras sustancias. Tendrá relación expresa con la propuesta determinada en el punto 5.2.4.

28 "Nueva escuela secundaria", Ciudad de Buenos Aires. Recuperado el 16 de febrero de 2018 de https://www.argentina.gob.ar/sites/default/files/sedronarorientacionparaelabordaje.pdf

29 http://www.buenosaires.gob.ar/sites/gcaba/files/dc_nes.pdf 
1.7 El trabajo y los estudios para el futuro. La escuela secundaria, mediante sus docentes comprometidos, tiene que desarrollarse formadora y tan creativa e innovadora que posibilite reducir la alta cantidad de abandonos que se producen en este nivel de enseñanza.

La escuela es la última oportunidad que tienen los adolescentes de recibir los necesarios conocimientos, las experiencias, vivencias, la motivación, para que acepten desafíos y los puedan resolver, y que puedan consolidar su identidad mediante una educación en valores, para prepararse para seleccionar su proyecto de vida. Así, decidirá qué carrera universitaria, especialidad, tecnicatura o trabajo formal se propondrá alcanzar para su futuro.

Será clave, en cada escuela secundaria, considerar la posibilidad de realizar viajes de estudios, campamentos, recorridos culturales mediante las visitas a museos, teatros, librerías, mientras que las visitas a empresas industriales o comerciales colaborarán para imaginar las prácticas educativas y la realización de proyectos sociocomunitarios, sobre los problemas clave sintetizados en el presente trabajo.

\section{Desde la salud pública}

Una definición de salud pública, de las más completas, es la siguiente: "La salud pública es el resultado del esfuerzo organizado de la sociedad, principalmente a través de sus instituciones de naturaleza pública para mejorar la salud de las poblaciones por todos los medios idóneos" (Guerra de Macedo, 2001). ${ }^{30}$

En el período 2010-2016, ${ }^{31}$ se observa un importante incremento del registro de venta de drogas en el barrio. En otras palabras, aumenta de manera significativa la proporción de hogares que perciben de manera directa o indirecta que en su barrio se venden drogas ilegales. A finales de 2016, casi 5 de cada 10 hogares identificaron la venta o tráfico de drogas en su calle, manzana o vecindario.

Esta dimensión es en parte condicionante en la problemática que hoy sufren los adolescentes, que influye en la familia, la escuela y la comunidad, como también en la violencia, los accidentes, el embarazo no intencional y el abandono escolar.
2.1. La atención a demanda. Ante las circunstancias que se evidencian desde hace años, desde la atención primaria de la salud, sus centros de salud y las unidades funcionales, se debería instrumentar la atención a demanda inmediata y registrar los casos que requieran el seguimiento.

2.2 Mejorar la accesibilidad. Es posible instrumentar la solicitud de turnos mediante la utilización de internet y las redes sociales. La mayor parte de los jóvenes pueden utilizar el celular como medio de comunicación, independientemente de su condición social.

2.3 Mayor empleo de las redes sociales. Ya se está haciendo capacitación, formación de empleados y profesionales mediante las redes sociales. Se debería utilizar las redes sociales, tanto en la escuela como en la salud pública, para asesorar sobre las distintas problemáticas críticas que hoy experimentan los adolescentes.

2.4 Promover la participación. Utilizar las salas de espera para organizar y desarrollar talleres, presentación de proyectos, planteo de situaciones críticas, respaldados por docentes, profesionales de la salud y expertos en Salud Pública.

2.5 Formación de líderes y comunicadores claves. Teniendo en cuenta las definiciones, tanto de los espacios educativos como de la salud pública, será imprescindible promover la formación de jóvenes que se destaquen en sus actividades habituales, para que difundan fuera de las unidades funcionales ideas constructivas, realistas, y resalten las ventajas de los hábitos de vida saludables. Se impulsará la participación en eventos deportivos, torneos intercolegiales, clubes y organizaciones sociales que promuevan el trabajo, microemprendimientos, buscando el apoyo de ONG, fundaciones y empresas que puedan auspiciar y apoyar financieramente estos proyectos.

\section{Referencias}

Álvarez, A., Cattáneo, V. Musacchio, O., \& Provenzano, B. (2015). Protocolo para la atención integral de las personas con derecho a la interrupción legal del embarazo. (2. ${ }^{a}$ ed.). Buenos Aires: Programa Nacional de Salud Sexual y Procreación Responsable.

30 Organización Panamericana de la Salud (2001). Educación en Salud Pública. Nuevas perspectivas para las Américas. Washington D.C.: OPS.

31 Resumen ejecutivo. "Barómetro del narcotráfico y las adicciones en la Argentina". Recuperado el 16de febrero de 2018 de https://www.researchgate.net/ publication/324213232_BAROMETRO_DEL_NARCOTRAFICO_Y_LAS_ADICCIONES_EN_LA_ARGENTINA. 
Amezcua, M., \& Gálvez Toro, A. (2002). “Los modos de análisis en investigación cualitativa en salud: perspectiva crítica y reflexiones en voz alta". Revista Española Salud Pública. Recuperado de http://scielo.isciii. es/scielo.php?script=sci_arttext\&pid=S1135-57272 002000500005

Bardin, L. (1979). Análise de Conteúdo. Lisboa: Ediçoes 70.

Bonfiglio, J.I., \& Houquebie, N.E. (2016). "Barómetro del narcotráfico y las adicciones en la Argentina". (Informe $n^{\circ} 1$ ). Buenos Aires: Konrad Adenauer Stiftung.

Bonfiglio, J.I., \& Rodríguez Espínola, S. (2016). "Barómetro del narcotráfico y las adicciones en la Argentina". (Informe n. ${ }^{\circ}$ 2). Recuperado de http://www.codajic.org/sites/ www.codajic.org/files/Bar\%C3\%B3metro\%20del\%20 Narcotrafico\%20y\%20las\%20Adicciones\%20en\%20 la\%20Argentina.pdf

Bonfiglio, J.I., \& Rodríguez Espínola, S. (2017). "Barómetro del narcotráfico y las adicciones en la Argentina". (Informe n. ${ }^{\circ}$ 4). Recuperado de http://wadmin.uca.edu.ar/public/ ckeditor/2017-Observatorio-barometro_NyA_N4. pdf

Bonfiglio, J.l., Rival, J.M., \& Rodríguez Espínola, S. (2016). "Barómetro del narcotráfico y las adicciones en la Argentina". (Informe n. ${ }^{\circ}$ 3). Buenos Aires: Konrad Adenauer Stiftung.

Dirección General de Cultura y Educación (2007). "Diseño curricular asignatura Construcción de Ciudadanía". Buenos Aires: Dirección General de Cultura y Educación.

Dirección General de Cultura y Educación (2007). "Diseño curricular para la ES. Construcción de ciudadanía, 1er a 3er año". Buenos Aires: Dirección General de Cultura y Educación.

Fondo de las Naciones Unidas para la Infancia (2017). "Una situación habitual: violencia en las vidas de los niños y los adolescentes". Recuperado de https://www. unicef.org/publications/files/Violence_in_the_lives_of_ children_Key_findings_Sp.pdf

Fondo de las Naciones Unidas para la Infancia (2017). "Una situación habitual: violencia en las vidas de los niños y los adolescentes". Recuperado de https://www. unicef.org/publications/files/Violence_in_the_lives_of_ children_Key_findings_Sp.pdf

Gobierno de la provincia de Buenos Aires (2007). "Diseño curricular para la Escuela Secundaria. Construcción de Ciudadanía 1er a 3er". Recuperado de

http://servicios.abc.gov.ar/lainstitucion/organismos/ consejogeneral /disenioscurriculares/ documentosdescarga/ secundariaciudadania.pdf

Gómez Escalonilla Lorenzo, B. (2017). "Medios de comunicación y consumo de drogas en la adolescencia". Recuperado de

http://publicacionesdidacticas.com/hemeroteca/articulo/ 080064/articulo-pdf

Hernández Sampieri, R., \& Fernández Collado, C., \& Pilar Baptista, L. (2014). "Metodología de la Investigación Científica". Recuperado de http://observatorio. epacartagena.gov.co/wp-content/uploads/2017/08/ metodologia-de-la-investigacion-sexta-edicion. compressed.pdf 


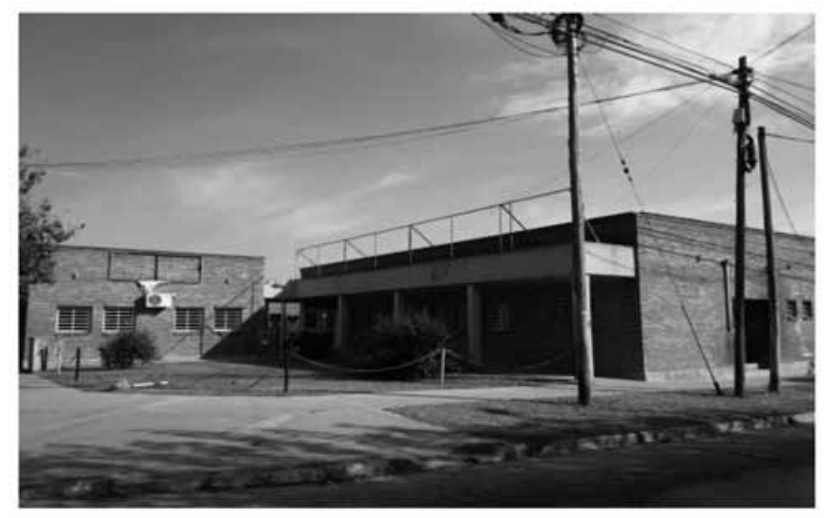

Unidad Funcional "Grand Bourg Sur". Grand Bourg. Calles Chacabuco y Luis Vernet. Partido de Malvinas Argentinas.

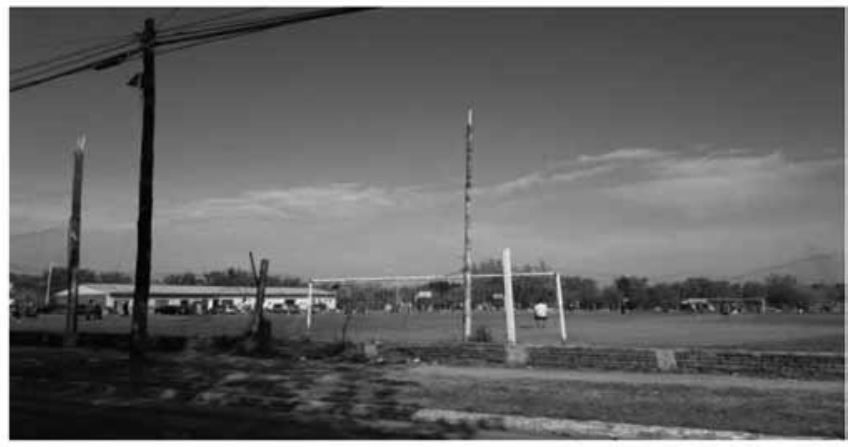

Campo de Deportes. Grand Bourg. Calles Chacabuco y Luis Vernet. Partido de Malvinas Argentina.

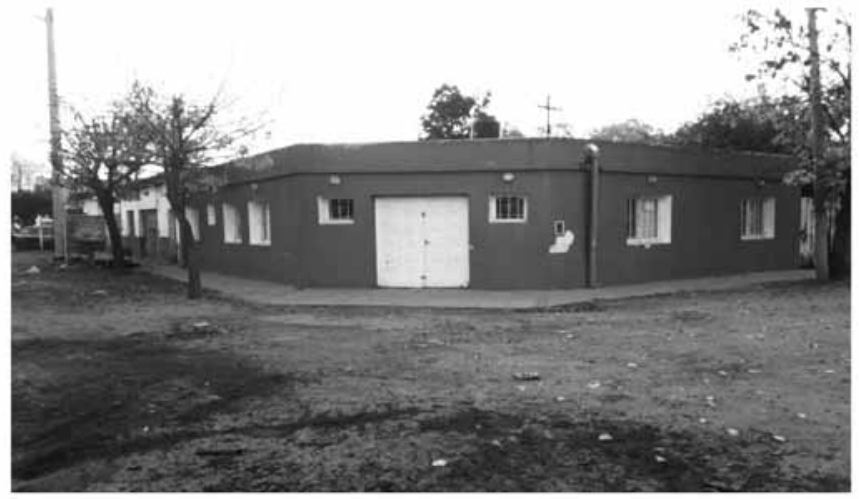

Unidad Funcional "El Camino". Calles Wilde y Asamblea. Grand Bourg. Partido de Malvinas Argentinas.

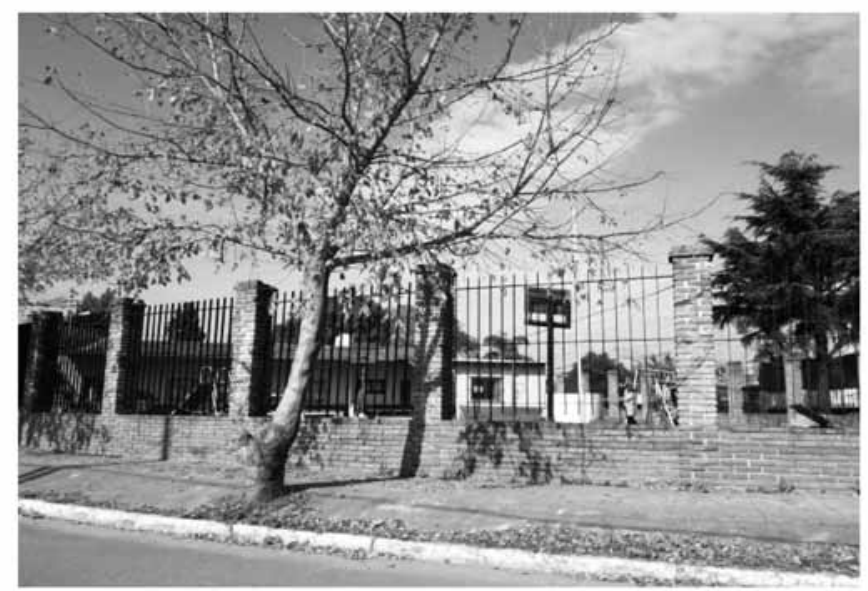

Unidad Funcional "Ampliación Devoto". Calles Paso de los Patos y Mario Bravo. Grand Bourg. Partido de Malvinas Argentinas. 


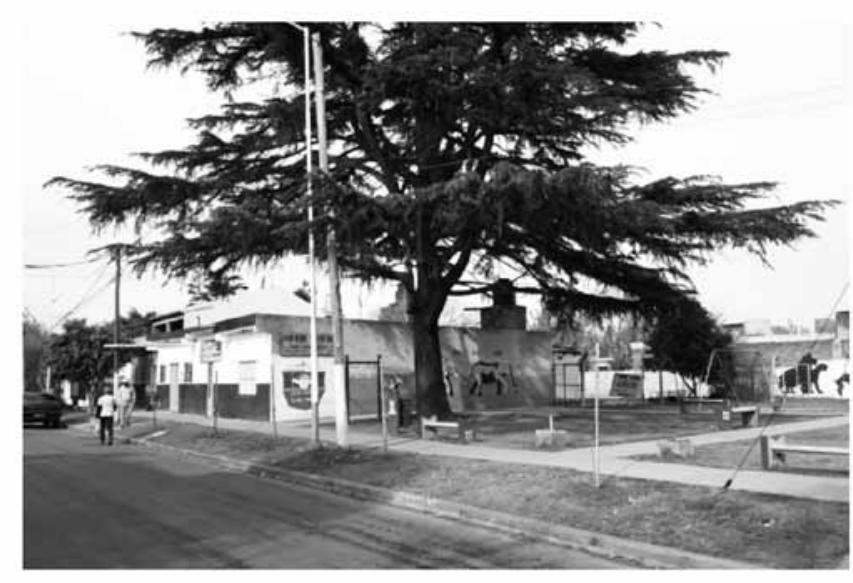

Unidad Funcional "El Sol". Calles Mahatma Gandhy y San Martín. Los Polvorines. Partido de Malvinas Argentinas.

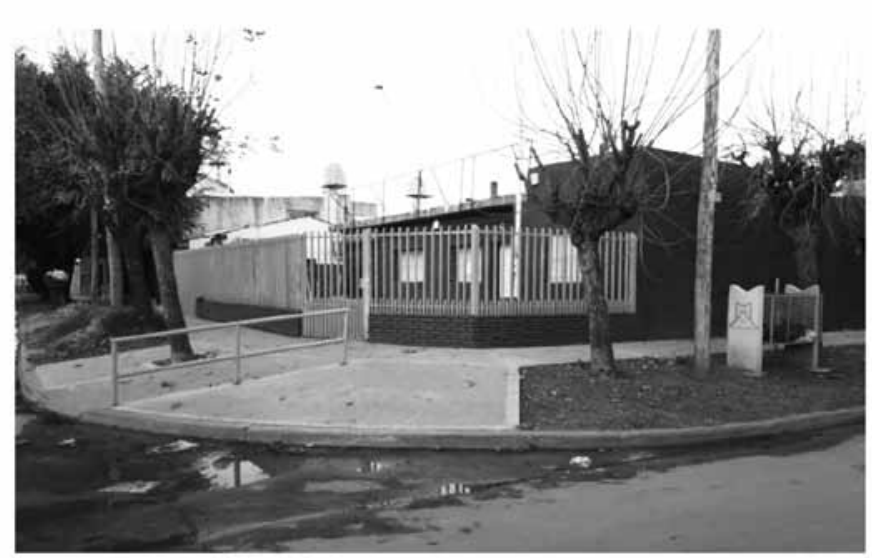

Unidad Funcional Unión y Progreso. Cerrito $n .^{\circ} 506$ y Dante Alighieri Los Polvorines. Partido de Malvinas Argentinas.

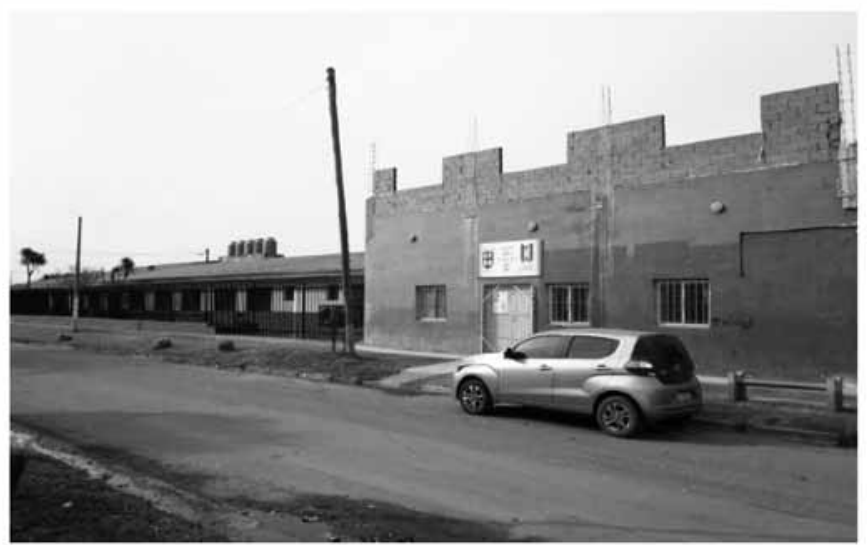

Unidad Funcional "Magdalena". San Ignacio n. ${ }^{\circ} 1461$ y Cerrito Bo. Magdalena. Los Polvorines 2. Partido de Malvinas Argentinas.

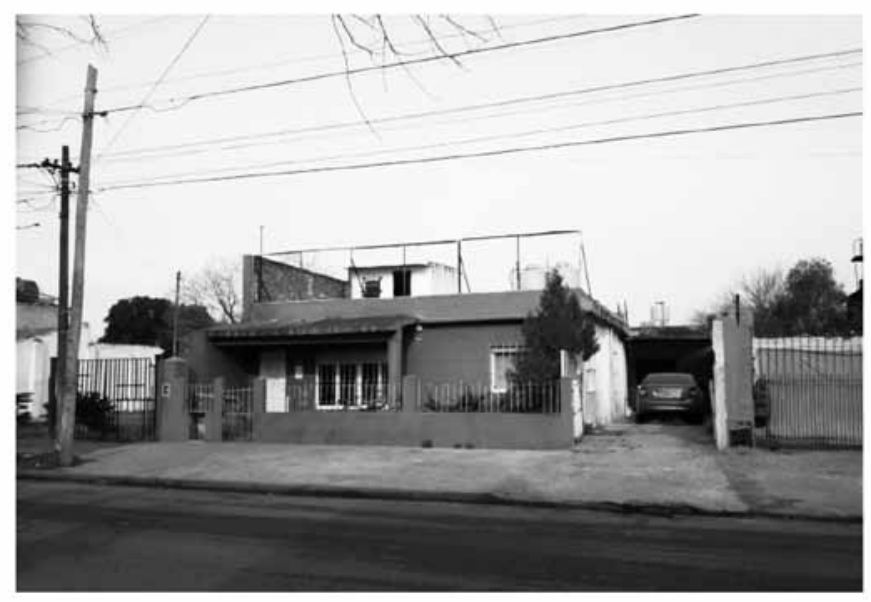

Unidad Funcional "Villa Mayo". Calle Eva Perón e/ Arquímedes y Sucre. Villa Mayo 1. Partido de Malvinas Argentinas. 